\title{
Imaginarios y cultura política de una élite costarricense. La construcción del poder simbólico de la familia Jiménez (1810-2010)
}

\section{Imaginary and Political Culture of a Costa Rican Elite. The Construction of the Symbolic Power of the Jiménez Family (1810-2010)}

Jorge Marchena Sanabria*

Resumen: El presente artículo analiza una parte de la cultura política, imaginarios y habitus de una de las familias de la élite costarricense, los Jiménez; en un periodo comprendido entre 1810 y el 2010, aproximadamente. El argumento central de esta exposición consiste en que los grupos dominantes conforman su poder a largo plazo y que, aparte del uso de diversas estrategias para acrecentar la riqueza material, también juega un papel dominante el poder simbólico, el cual se puede encontrar en las formas en que pactan sus matrimonios, alianzas, la mistificación de sus miembros, las prácticas caritativas, entre otros. Todo esto les permite acumular prestigio, a la vez que intentan legitimar el poder acumulado ante rivales y las clases subalternas. Por último, esta investigación se realizó retomando fuentes de archivos, notas hemerográficas, biografías y notas luctuosas.

Palabras claves: historia; poder; cultura política; élite; democracia; hegemonía; Costa Rica.

\begin{abstract}
This article analyzes a part of the political culture, imaginary and habitus of one of the families of the Costa Rican elite, the Jiménez, in a period between 1810 and 2010, approximately. The central argument of this paper is that the dominant groups make up their long-term power and that apart from the use of various strategies to increase material wealth, symbolic power also plays a dominant role, which can be found in the forms in which they agree their
\end{abstract} versidad Nacional (UNA), Costa Rica. Docente en la Sede de Occidente de la Universidad de Costa Rica (UCR), Costa Rica. Colaborador del Centro de Investigación en Identidad y Cultura Latinoamericanas (CIICLA) de la UCR. Correo electrónico: jmarsan85@yahoo.com. 
marriages, alliances, the mystification of their members, charitable practices, among others. All this allows them to accumulate prestige while trying to legitimize the accumulated power against rivals and the subaltern classes. Lastly, this research was carried out taking up sources of archives, press notes, biographies and mournful notes.

Keywords: History; Power; Political Culture; Elite; Democracy; Hegemony; Costa Rica.

\section{Presentación}

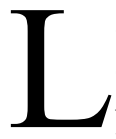

a familia Jiménez aquí analizada — por lo demás, un apellido muy común en Costa Rica-, es una agrupación originaria del periodo de conquista y mantuvo una posición privilegiada a lo largo del dominio colonial español ${ }^{1}$ y luego, tras la Independencia en 1821, se convirtió simplemente en una agrupación importante de la vieja ciudad de Cartago. Entrado el siglo XX y hasta el presente, ascendieron hasta convertirse en una élite de poder de primer orden; por mucho, una de las más ricas y políticamente influyentes en todo el istmo centroamericano. Para ejemplificar esto, se puede citar que su patrimonio está conformado por sendas inversiones en la Florida Ice and Farm Company, FIF$\mathrm{CO}$ - conocida como la Cervecería Costa Rica-, el Grupo Nación que publica los periódicos de mayor alcance del país, la Hacienda Juan Viñas que produce azúcar y café de exportación, así como panaderías, supermercados, franquicias de comidas rápidas, entre muchos otros negocios. ${ }^{2}$

En el aspecto político, en el siglo XIX y la primera mitad del siglo XX, la familia contó con dos figuras que alcanzaron la silla presidencial, Jesús Jiménez Zamora y Ricardo Jiménez Oreamuno. El grueso de la parentela principal ${ }^{3}$ ha ejercido como ministros, viceministros, congresistas, asesores presidenciales y en las últimas tres décadas, han aportado grandes sumas de dinero a distintas campañas electorales; inclusive, en sus mansiones se toman decisiones

1 Manuel de Jesús Jiménez Oreamuno, «Domingo Jiménez», Revista de Costa Rica, n. 8 y 9 , año II (abril-mayo, 1921): 229-235.

2 Referencias acerca de sus participaciones empresariales se encuentran en: La Nación, "En cumplimiento de lo que dispone la Ley N. ${ }^{\circ} 6220$ del 20 de abril de 1978, publicada en el alcance N. ${ }^{\circ} 78$ de la Gaceta No. 89, La Nación, S.A., da a conocer la lista completa de las personas físicas y de los accionistas de las personas jurídicas dueñas de acciones de esta empresa”, 30 de junio 2010, 20A-21A, FIFCO. FIFCO, Viviendo nuestro propósito. Reporte integrado 2015 (San José, Costa Rica: FIFCO, 2015) y Carlos Porras Jara, Los primeros cien años de la Florica Ice \& Farm Co. (San José, Costa Rica: MasterLitho, 2010).

3 Cuando en este texto se menciona a la familia Jiménez, se refiere a los descendientes directos de Ramón Jiménez y Robredo a partir del siglo XIX, incluyendo: Jiménez Zamora, Jiménez Oreamuno, Jiménez Ortiz, Jiménez de la Guardia, Jiménez Borbón y Jiménez Solera. En los anexos se incluyen diagramas mostrando tanto sus ancestros de origen colonial, como los miembros mencionados en este artículo. Por otra parte, es importante señalar que las figuras de Jesús Jiménez Zamora y sus hijos, Manuel de Jesús y Ricardo Jiménez Oreamuno, aunque son sin lugar a duda trascendentales, en este artículo son personajes secundarios, pues la rama en la que nos enfocamos es la antes descrita y una de las hipótesis es que Jesús y sus hijos, estuvieron supeditados a esta y pudieron ejercer como representantes politicos. 
trascendentales en cuanto a la conformación de papeletas y el impulso de políticas públicas, como lo fue el Tratado de Libre Comercio entre los Estados Unidos, Centroamérica y República Dominicana, ratificado en 2007; aspectos que más adelante se analizarán.

En el presente artículo, nos centraremos en presentar algunos rasgos esenciales de su cultura política e imaginarios de élite. Estos aspectos permiten comprender desde otro plano, sus proyectos empresariales y la visión de país que tratan de impulsar o convertir en hegemónica. La tesis central de este trabajo se concentra en rastrear el poder simbólico y las prácticas de distinción — similares al habitus de Bourdieu - que conforman a una élite de poder, las cuales dan paso, precisamente, a fortalecer la reproducción de su riqueza económica y colaboran en su perpetuación, ya que les otorgan influencia, prestigio y nexos, tanto para sus negocios, como para maximizar el control sobre organizaciones como el Estado o inclusive, medios de comunicación y partidos políticos.

A partir de esto, es importante señalar que las variables que explican esta cultura de élite cambian y se readaptan conforme a los procesos históricos que experimenta el país y la familia estudiada en particular; aunque, lo que es sumamente llamativo, es la perduración de valores que se supondrían como extintos o propios de otro periodo, es decir, anacronismos. De esta forma, al despuntar el siglo XIX los principales valores que se usufructuaban era el honor, el prestigio ancestral, la moral cristiana, así como la imagen patriarcal forjada por los siglos de la Colonia, a esta se le sumaría, tras la Independencia, el servicio a la patria, su rol como funcionarios públicos, especialmente en el campo del Derecho. Ya entrado el siglo XX y con una mayor base de poder simbólico acumulado, el rol de líderes honrados, sumado a sus calidades de pioneros y filántropos, acentuaron su poder entre sus pares de la élite. En tiempos actuales, este acervo de simbolismos y mitos, les han permitido perpetuar su dominio y colocarlos en un sitial privilegiado, como la facción hegemónica dentro de la clase alta costarricense.

En los aspectos teóricos, se partió de un concepto integrado de élites y de cultura política. En cuanto al primero, se le considera integrado o sintético, ya que se parte de un estudio de élites basado en distintos teóricos sociales del siglo XX. ${ }^{4}$ De esta forma, élite — moderna, no colonial—, se refiere a un estrato de la comúnmente denominada clase alta, pero que cuenta con amplios recursos o potencialidades, así como una posición de liderazgo al interno de ésta. Igualmente, alcanza mayores cuotas de poder, que se traducen en dominio político, social, riqueza material, prestigio, tradición - apelar a genealogías- y en algunos casos específicos, conexiones eclesiásticas e intelectuales. ${ }^{5}$ Asimismo, la

4 Tales como Pareto y Mosca. Irving Zeitlin, Ideología y teoría sociológica (Buenos Aires, Argentina: Amorrortu, 2006), 181-246.

5 Retomando parte de la jerarquía de élites, planteada por Mills, en la que se enfatiza la existencia de una élite que concentra varios tipos de poder e influencia. Charles Wright Mills, La élite del poder (México, D.F.: Fondo de Cultura Económica, 1975). 
élite no es singular —un sujeto o líder erróneamente considerado como extraordinario - sino que implica una serie de personas y familias entrelazadas, por lo general, vía matrimonial o como socios en empresas. Otro aspecto clave es que las élites no son producto de atributos sobre naturales o de caprichos del azar, al contrario, se forman históricamente y muchas veces, este proceso implicó un despojo inicial, el monopolio de recursos - tierra, capitales, conocimientos...y un proceso de alianza con otros estratos dominantes y tras un cierto periodo de tiempo, se consagran como élite. ${ }^{6}$ Lo anterior implica que dado el contexto en que se desenvuelva, un grupo de este tipo bien puede entrar en decadencia y por múltiples razones extinguirse - guerras, malas inversiones, muerte de sus miembros más capacitados, entre otros-; al mismo tiempo, para mantener su posición, luchan por la hegemonía contra otras facciones locales o foráneas de la clase alta o inclusive con élites rivales.

Como ya fue mencionado líneas atrás, un factor central que se pretende revisar en este artículo, gira alrededor del poder simbólico, con ramificaciones tales como el prestigio y las mitificaciones -el arquetipo del hombre poderoso - ${ }^{7}$ Las élites son una muestra clara de la desigualdad social, poseen mayores recursos y privilegios que el grueso de la sociedad, especialmente, en casos como el latinoamericano, con grandes masas sumidas en la miseria y la pobreza. ${ }^{8}$ Por ende, para sostener su poder y evitar cuestionamientos serios a su hegemonía, estos grupos dominantes recurren a discursos justificantes y en términos de Bourdieu, a habitus, mecanismos de diferenciación que acentúen su poder, el cual muchas veces, es imaginario o un mito. ${ }^{9}$ Por un lado, son discursos que los tratan de colocar como sujetos excepcionales y superiores a la media, pioneros o en este caso en particular, como padres de la patria. Además, construyen narrativas - que difunden a través de sus propios medios de comunicación y biografías - que los sobredimensionan y los postulan como empresarios ejemplares o políticos insignes. Por otra parte, sus hábitos cotidianos deben generar una estricta diferencia con el resto del cuerpo social, por lo común, siendo receptores de una educación más sofisticada, partícipes de la filantropía, reconocimientos o premios sociales - incluyendo el servicio público mandatorio-, la asistencia a clubes y otras extravagancias.

6 Dicho de otra manera, o como un complemento, un grupo con riqueza o fama, pero con pocos años o décadas de existencia, más bien se catalogaría — en esta postura - como una mera facción de la clase alta, aunque en pugna por consagrarse y eventualmente, obtener la hegemonía.

7 Dado que en el presente artículo se revisa la construcción de discursos que encumbran e inventan élites, los aspectos políticos y económicos en la formación de estos grupos privilegiados, son marginados.

8 Para más detalles de la historia y tensiones latinoamericanas se puede consultar: Manuel Lucena Salmoral et al., Historia de Iberoamérica. Tomo III (Madrid, España: Cátedra, 2008).

9 Antonio Álvarez Sousa, «El constructivismo estructuralista: La teoría de las clases sociales de Pierre Bourdieu», REIS: Revista Española de Investigaciones Sociológicas, 75 (1996): 145-172, http://www.reis.cis. es/REIS/jsp/REIS.jsp?opcion=articulo\&ktitulo=1163\&autor=ANTONIO+\%C1LVAREZ+SOUSA. 
De forma sintética, se puede anotar que la cultura política, se refiere por mucho a la introducción del concepto de cultura en el campo político y de los estudios acerca de la democracia. Esta ola de estudios se asentó principalmente en Occidente durante la Guerra Fría y fue conocido inicialmente como Cultura Cívica. Esta misma, implicaba abandonar el estudio de las instituciones políticas y concentrarse en conductas, valores, motivaciones, expectativas, entre otros, de los distintos estratos sociales. El problema fundamental, radicó en que este enfoque privilegió en demasía los comportamientos — behavior - y tendió al aislamiento con respecto a la historia y la política. ${ }^{10}$ Para el abordaje del tema de la cultura política, se debe tener en consideración, que la cultura como tal, es un término imperial, es decir abarca diversos ámbitos: desde las experiencias sociales, las prácticas y formas de vida; hasta las costumbres, relaciones e interacciones entre sujetos o colectivos, entre otros. ${ }^{11}$ Entonces, al referirse a cultura política, se pueden incluir las experiencias, prácticas cotidianas e interrelaciones de las élites en el mundo político; igualmente, se puede visualizar como una forma de estudiar la cultura misma de los grupos dominantes.

Metodológicamente, se recurrió a un análisis y reconstrucción de procesos, la heurística histórica y rastrear la secuencia de sus prácticas hasta el presente. Se utilizó una prosopografía - y datos genealógicos-, pero limitada solo a unos pocos miembros de la familia estudiada, para evitar que los datos se tornaran inmanejables. Las principales fuentes empleadas consistieron en: biografías, libros y artículos académicos, notas periodísticas, documentos de la Asamblea Legislativa, sitios de internet, entre otros..$^{12}$ Un aspecto central sobre el que se debe llamar la atención, es que esta indagación de las prácticas y valores de élites no es exhaustiva, fue conformada a partir de la información localizada, muchos otros ejemplos han ocurrido y se mantienen hasta hoy; futuras investigaciones deberían dar luces al respecto.

\section{Discursos apologéticos que erigen élites de poder}

Antes de entrar de lleno con la construcción simbólica de una élite, es importante anotar que la Costa Rica decimonónica, es una que se encuentra en plena transición, entre la Colonia y la Modernidad; aunque, este fue un proceso que no se completó del todo. Y es que las viejas autoridades coloniales pudieron extinguirse, o más bien, fueron reincorporadas a la República, mientras que el tabaco y otros productos relativamente fallidos dieron paso — con el oro de las minas del Aguacate

10 Javier de Diego Romero, «El concepto de "cultura política" en ciencia política y sus implicaciones para la historia», Ayer, 61, n. 1 (2006): 236, https://www.jstor.org/stable/41324963.

11 Stuart Hall, Sin garantias. Trayectorias y problemáticas en estudios culturales (Popayán, Colombia: Editorial de la Universidad del Cauca, 2014), 56.

12 Se debe señalar que las fuentes consultadas son de índole variada, ya que rastrear el poder simbólico, no es un tema común de los documentos públicos y de archivos, muchas «pistas» se encuentran en biografías con altas cargas de mistificaciones-, notas promocionales de periódicos y revistas de la época, así como la imperiosa necesidad de rastrear pequeñas menciones en fuentes secundarias. 
de por medio- al esplendor cafetalero de mediados de la centuria. Las viejas familias ancladas en el pasado continuaron con viejas prácticas coloniales y, por ello, se robustecieron con los influjos de sangre joven que aportaron los grupos inmigrantes europeos en estos años, especialmente, germanos - Rohrmoser, Niehaus, Peters...- y españoles-centroamericanos - Montealegre- . Asimismo, mientras que el istmo se desangraba por las guerras intestinas, el novel Estado se preparaba para estrechar lazos diplomáticos con las potencias de la época y, a la vez, implementar una variante tropicalizada de la democracia burguesa, una que contaría con fuerte protagonismo de los descendientes de los Jiménez aquí estudiados.

De esta forma, al iniciar el siglo XIX y en vísperas de la Independencia, la familia Jiménez se encontraba en una posición de relativa comodidad. Primero, su apellido poseía un importante valor dentro de los imaginarios de la época, puesto que se remontaba a los primeros conquistadores y encomenderos que arribaron al Valle Central en el último tercio del siglo XVI. ${ }^{13}$ Segundo, su riqueza, si bien no era desbordante, incluía algunas casas en el centro de la ciudad y, sobre todo, fincas en los alrededores de Cartago. ${ }^{14} \mathrm{La}$ otra fuente de ingresos, derivaba de los puestos políticos que comúnmente desempeñaban los miembros del clan; por ejemplo, Ramón Jiménez y Robredo (1779-1851) fue el penúltimo gobernador interino de Cartago y también había sido alcalde de la localidad. ${ }^{15}$ Pero más que destacar su riqueza material, el objetivo es señalar los recursos inmateriales o simbólicos que lograron reunir.

Para empezar, debe precisarse que un bastión fundamental del poder de los Jiménez ha radicado en las relaciones sociales tejidas a lo largo de siglos. De esta forma, se puede citar que Ramón contrajo nupcias con Joaquina Zamora y Coronado (1788-1834), quien era parte de los clanes más influyentes de Cartago. Ramón también fue cuñado de don Joaquín de Oreamuno y Muñoz, líder «conservador» de los golpistas cartaginenses de 1823, quien se había casado con Florencia Jiménez de Robredo; la familia Oreamuno se destacó entre los primeros inversionistas de las minas del Aguacate, las cuales permitieron capitalizar a la élite y favorecer sus tempranas aventuras cafetaleras. ${ }^{16}$

Precisamente, estas prácticas matrimoniales permiten concentrar la riqueza y evitar peligrosas divisiones del patrimonio — particiones de fincas - , herencias

13 Los Jiménez arribaron en 1a década de 1570 a la que sería la provincia colonial de Costa Rica, especialmente, el que sería encomendero, Domingo Jiménez. Ya a mediados del siglo XVII, destacaba la figura de su descendiente, Domingo Jiménez Maldonado, comerciante de Cartago. Manuel de Jesús Jiménez Oreamuno, Noticias de antaño. Tomo I (San José, Costa Rica: ENUED, 2011), 191-192. Aunque, debe enfatizarse que la historia colonial de los Jiménez no es parte de los objetivos de esta investigación.

14 Archivo Nacional de Costa Rica —en adelante, ANCR—, Serie Protocolos Coloniales n. ${ }^{\circ} 1147$ (San José, Costa Rica: Archivo Nacional de Costa Rica, 16 de diciembre de 1848), folios 153v-157v. Otra finca destacable, era la Hacienda Curridabat, ubicada en el cantón homónimo, fue una importante productora de café y la familia mantiene algunos fragmentos hasta el presente.

15 José Francisco Sáenz Carbonell, Don Joaquín de Oreamuno y Muñoz de la Trinidad: vida de un monárquico costarricense (San José, Costa Rica: ENUED, 1994), 63 y 101.

16 Carlos Araya Pochet, «La minería en Costa Rica (1821-1843)», Revista de Historia, n. ${ }^{\circ}$ (enero-junio, 1976): 116, https://www.revistas.una.ac.cr/index.php/historia/article/view/11925. 
desproporcionadas que solo benefician a un heredero y otros perjuicios. Ramón Jiménez tuvo un legado anclado en tiempos coloniales, ya que podía reclamar una genealogía entroncada con los primeros conquistadores -véase el anexo $1-\mathrm{y}$ que, además de los citados bienes inmuebles, consistía en el acceso al conocimiento - lo cual le permitió ejercer cargos políticos complejos-, amplias conexiones-parentesco y el dominio de las armas. ${ }^{17}$ Pero la riqueza material no era lo único que se heredaba, por mucho, los bienes intangibles podían ser más apetecidos, entre estos, el título de "padre de la patria".

Este adjetivo fue adquirido en gran parte, gracias a la participación de Jiménez en las primeras juntas independistas que confeccionaron los tempranos códigos jurídicos que regularían el devenir de Costa Rica. Aunque, en la práctica, su papel en estas entidades fue de suplente y más adelante, en el decenio de 1830, durante los conflictos por el establecimiento definitivo de la capital, Jiménez figuró en las listas de enemigos del triunfal caudillo josefino, Braulio Carrillo Colina; pronto fue reincorporado a las filas de las familias preponderantes de Cartago, pero que engrosaron el bando perdedor. ${ }^{18}$ Es evidente que Ramón fue un personaje secundario y que figuraba entre los «derrotados», por ende, su título de fundador patrio, es un poco impreciso. Aquí, es donde entran las construcciones míticas y los imaginarios; en las siguientes décadas y más importante, hasta llegar al siglo XX, los apologistas —incluyendo miembros de la misma familia, como Manuel de Jesús Jiménez- se encargaron de construir una figura exaltada, con palabras de un corte glorioso:

Educado en el ambiente patriarcal de la histórica ciudad, con austeras tradiciones de hogar y de estirpe, fue el señor Jiménez un hombre de carácter entero, de conducta correctísima, de opiniones bien definidas y un alto funcionario que en la vida política de la nación supo imprimir a sus actos un sello de altiva independencia. ${ }^{19}$

De esta forma, se esgrimían todos los elementos que debían ser preservados por sus descendientes: patriarca, estirpe, carácter, altivez, servicio público. Sobra anotar que estas caracterizaciones tenían un fuerte eco colonial o romántico y esto debe llamar poderosamente la atención, pues este párrafo fue escrito bien entrado el siglo XX, y la memoria no solo se preservó, se exageró. ¿Cómo se resguardó el legado? Sin duda las presidencias de Jesús Jiménez y su declaratoria de Benemérito de la Patria jugaron un papel central, incluso en su honor se

17 Eduardo Madrigal Muñoz, «Poder económico y lazos sociales de una élite local en los últimos años del régimen colonial y en la Independencia: Costa Rica, 1821-1824», Caravelle, 101 (2013): 91, doi: https:// doi.org/10.4000/caravelle.575.

18 Documentos para escribir la historia de la revolución de Costa Rica, que estalló en fin de septiembre del año de 1835 copiados por un costarricense de los originales, que obran en el archivo del gobierno e impresos en San José a 15 de enero de 1836 (San José, Costa Rica: Imprenta de la Paz, 1836), 12, 28-29 y 36.

19 «Don Ramón Jiménez», Revista de Costa Rica, n. ${ }^{\circ}$, año III (15 de setiembre de 1921): 25. 
nombró un cantón de Cartago $;^{20}$ a la vez, la labor de juez de la Corte Suprema de Justicia del destacado Manuel Vicente Jiménez Oreamuno — nieto de Ramón-, también abonó para maximizar los relatos de Ramón Jiménez.

Otros aportes inmateriales se pueden encontrar en la segunda mitad del siglo XIX, de la mano del hijo primogénito de Ramón, José Manuel Jiménez Zamora (1813-1888). A partir de este, se estableció una de las prácticas más llamativas de la que se podría calificar como «línea principal» de los Jiménez y consiste en la denominación de Manuel, la cual no se aplica exclusivamente al primogénito, sino a gran parte de los varones. Esta costumbre se asemeja a los monarcas del Antiguo Régimen y era utilizada para construir una imagen de una dinastía continua y sempiterna; además, construía la memoria de una familia de hombres poderosos y entregados a la patria costarricense. A largo plazo y en aspectos centrales de la riqueza familiar, el citado José Manuel tuvo una participación limitada, precisamente, fue el periodo en que su linaje se encontraba a la baja y sufrió el impacto negativo del derrocamiento de su hermano, Jesús Jiménez en 1871.

A esto se sumaba que los negocios se encontraban estancados y, a pesar de su rápida incorporación al negocio cafetalero, los Jiménez eran actores marginales en el escenario de las élites decimonónicas. A finales de este siglo, destacaban por su apego a los viejos valores de origen colonial, es decir, se podían relacionar fácilmente con los grupos conservadores de la vieja metrópoli, puesto que se esmeraban en colaborar con el culto religioso de la ciudad. Por ejemplo, en 1887, la lujosa imagen de la Virgen de Nuestra Señora de los Siete Dolores, traída desde Italia con un manto de hilos de oro y que estaba resguardada en la iglesia de San Francisco, era un regalo de Dolores Oreamuno Carazo, esposa de José Manuel. A su vez, los Jiménez fungían como mayordomos del Convento de los Padres Capuchinos. Por su parte, la Cofradía de la Virgen de los Dolores, fundada en 1910, fue una iniciativa de algunas mujeres de la familia, incluyendo a Dolores Jiménez de Sancho e incluía a Isabel Montealegre de Jiménez y María Tinoco de Jiménez, entre otras. ${ }^{21}$

Esta unión entre élites y fervor religioso alcanzaba un tono mayor en el mausoleo de la familia, encargado por José Manuel. Este monumento es descrito en los siguientes términos:

[...]destaca por su tamaño y riqueza ornamental, con una importante variedad de símbolos apropiados a la temática funeraria. Algunos de estos símbolos son el ancla, el caduceo, la clepsidra o reloj de arena alado, las coronas de laureles y, por supuesto, la cruz. ${ }^{22}$

20 Una biografía y cargos de Jesús Jiménez se encuentra en: Guillermo Brenes Tencio, «La nación costarricense en duelo: los funerales del expresidente Jesús Jiménez Zamora (1897)», Acta Republicana Política y Sociedad, n. $^{\circ}$ 5, año 5 (2006): 3-15.

21 Mynor Esquivel y Jorge Guzmán Loría, Cartago, «Convento de los padres capuchinos: una virgen de talla italiana», Revista Pasos de Fe (12 de setiembre 12 de 2012): párrafos 2 y 3, http://www.revistapasosdefe. $\mathrm{com} / \mathrm{p}=3285$.

22 Guillermo Brenes Tencio, «Ángeles funerarios del Cementerio General de Cartago, Costa Rica», Boletín de Monumentos Históricos, $\mathrm{n}^{\circ}$ 19, tercera época (mayo-agosto, 2010): 150. 
El autor de la cita, Brenes Tencio, señalaba que la presencia de ángeles sosteniendo guirnaldas, coronas de flores y afines, se utiliza para presumir de una vida virtuosa. La tumba de Jiménez era muestra de la vida de un hombre prócer y que se consideraba, a sí mismo, encaminado al paraíso celestial; o cuando menos, eso es lo que se buscaba proyectar.

Aunque Jiménez Zamora fue opacado por su hermano, el expresidente Jesús, su hijo Manuel Vicente Jiménez Oreamuno (1844-1908) retomó la senda del enriquecimiento familiar. Su actuación pública se tornó arquetípica para sus descendientes, pues fue uno de los principales juristas de la época y desempeñó casi todos los cargos que el poder judicial ofrecía a finales del siglo XIX; incluso, presidió el Colegio de Abogados a inicios de la siguiente centuria. ${ }^{23}$ Aunque el mundo colonial se suponía extinto, Manuel Vicente era un fiel representante de este, como el profesor Madrigal señalaba, una de las características centrales de la élite cartaginesa - ya en este momento, seriamente debilitada - era su monopolio o acceso preferencial al conocimiento. Manuel Vicente poseyó un manejo envidiable del derecho y, por ello, pudo demandar exitosamente al Estado por daños a sus fincas en Curridabat ${ }^{24}$ y en la década de 1890, protagonizó una serie de especulaciones o compraventas con tierras en la futura Turrialba, que le permitieron a su familia contar con una base para la posterior acumulación de capitales. ${ }^{25}$

Una vez más, no fueron sus cualidades de abogado ni su acceso a la educación lo que fue destacado en sus panegíricos, sino las típicas alabanzas que su abuelo también recibió, por eso Manuel fue calificado como un «...varón austero, justo y sabio, que luce en las páginas de la Historia con un laurel inmarcesible». ${ }^{26}$ Otros textos fueron más explícitos:

Perteneciente el Licenciado Jiménez a una de las mejores familias de Cartago, educado en un ambiente religioso de la más pura moral[...] ijamás cometió una mala acción! [...]deja una familia rodeada de las mayores consideraciones sociales[....$^{27}$

Ahora, las palabras claves correspondían a sabio, justo, religión y moral; más llamativo, era considerado como parte de las mejores estirpes de la otrora capital de Costa Rica. Hiperbolizar a los miembros del clan, elevarlos a un estatus

23 Pandemónium, «El Lic. Manuel Vicente Jiménez», año II, marzo de 1903: 635. Se puede sintetizar que fue juez, magistrado, ministro y presidente del Colegio de Abogados.

24 ANCR, Serie Juzgado de lo Contencioso Administrativo N. 3833 (San José, Costa Rica: ANCR, 22 de agosto de 1891).

25 Dado la extensión del tema en particular, así como el enfoque en el tema de cultura de élites de este artículo, no se ofrecen mayores detalles de esta compraventa, pero el grueso del caso fue analizado en la investigación: Jorge Marchena Sanabria, Formación histórica de las élites costarricenses a través del estudio de caso de la empresa "Florida Ice and Farm Company" y su asociación con la familia Jiménez. (En prensa). Producto del proyecto de investigación 818-B6-090 del CIICLA, Universidad de Costa Rica.

26 Jesús Mata Gamboa, Monografia de Cartago (Cartago, Costa Rica: Editorial Tecnológica, 1999), 50.

27 Páginas Ilustradas, "Licenciado don Manuel Vicente Jiménez", n. ${ }^{\circ}$ 182, año V, 26 de enero de 1908: 3041. 
de hombres supremos, es una obligación de todos estos relatos biográficos. Por otra parte, Manuel Vicente tuvo un aporte significativo al caudal de riquezas que heredó y estriba en su cultura política propiamente dicha. Sentó un fuerte precedente, pues en 1870, como miembro del Congreso, aceptó cederle poderes casi dictatoriales a su tío Jesús; pocos meses más tarde se encontraba en la lista de «hombres de confianza» del general Tomás Guardia Gutiérrez. Por supuesto, esto era una especie de simbiosis, pues Guardia ganaba un valioso aliado, que podría acelerar el proceso de reconciliación. De todas formas, esto se convirtió en tendencia. Veinte años después, en la administración dictatorial de José Joaquín Rodríguez (1890-1894) y entre cuyos principales opositores figuraba el primo de Manuel Vicente, Manuel de Jesús Jiménez Oreamuno — hermano mayor de Ricardo- Vicente se puso del lado del déspota, ya que figuró como un fiel secretario de relaciones exteriores. ${ }^{28}$

Décadas atrás, el afectado había sido Jesús, ahora le correspondía a su hijo, mientras que sus primos se alineaban con la figura política dominante. Curiosamente, la línea Jiménez principal se nutrió, sobremanera, de la herencia inmaterial de sus primos presidenciales, Jesús y Ricardo e incluso, del escritor Manuel de Jesús. Y es que este último se consagró como intelectual a principios del siglo $\mathrm{XX}$ y hasta fue reconocido como uno de los pioneros en el estudio histórico costarricense. Sus hagiógrafos afirmaron que era un orador nato y prístino: «Bastaba que se sospechara que iba a hablar don Manuel de Jesús para que de bote en bote se llenaran las galerías del Congreso». Otros, como Valeriano Fernández Ferraz lo adularon al extremo: «El primer orador costarricense, no vacilo en afirmarlo. Clara luz de pensamiento; correctísima palabra. Sus bellas producciones, hijas del talento natural y la más estudiosa constancia». ${ }^{29}$ No obstante, a pesar de las sendas obras escritas en su honor y la abultada literatura en torno a su hermano, el célebre Ricardo Jiménez, esta facción de la familia podría ser catalogada como marginada, sobre todo en términos económicos.

$\mathrm{Al}$ analizar las redes de poder y la conformación de élites, el parentesco no se debe utilizar como un argumento inescrutable para establecer relaciones o alianzas. En su obra clásica acerca del Renacimiento italiano en el siglo XV, Jacobo Burckhardt detallaba los conflictos a lo interno de las familias, que podían desembocar en violencia y muerte..$^{30}$ Por supuesto, este es un ejemplo extremo, pero muestra que la sangre no garantiza la concordia, especialmente cuando se trata de grupos con cuantiosas riquezas. Más adelante, en la primera mitad del siglo XX, Ricardo Jiménez Oreamuno se convirtió no solo en un exitoso político, sino en uno populista y excéntrico, que bien pudo despertar el enojo de su

28 Pedro Rafael Gutiérrez, 100 años de historia a través de La Prensa Libre (San José, Costa Rica: Impresora Costarricense S.A., 1989), 37.

29 Luis Barahona Jiménez, Manuel de Jesús Jiménez (San José, Costa Rica: Departamento de Publicaciones del Ministerio de Cultura, Juventud y Deportes, 1976), 22.

30 Jacob Burckhardt, La cultura del Renacimiento en Italia (Madrid, España: Editorial EDAF, 1982). 
parentela y recibir una variante de exilio: fue marginado de los medios de producción más valiosos y tuvo que conformarse con fincas supuestamente «precarias» en el cantón de Tucurrique. ${ }^{31}$ Otra interpretación podría señalar que Jesús Jiménez y sus hijos recibieron las responsabilidades políticas de la familia, el mismo Jesús trató de que la línea férrea hacia el Caribe favoreciera las tierras turrialbeñas de su hermano y sobrinos; ${ }^{32}$ mientras que Ricardo, en el decenio de 1930, apoyó, desde la Presidencia de la República, la creación de la Oficina de Defensa del Café, que lideraba su primo, Manuel Francisco Jiménez Ortiz.

Además de señalarse esta peculiar designación de roles, resuena con fuerza que la familia pareciera tener un «designio supremo». Para aclarar, los Jiménez como una estirpe de varios siglos y un amplio poder político-económico, podrían operar con proyectos de largo alcance en el tiempo, en donde cada miembro [varón] funge un rol asignado - e irrenunciable - en la preservación de sus privilegios. En años más recientes, otros Jiménez han mostrado variantes de esta práctica; ejemplos que más adelante se abordarán. ${ }^{33}$ De esta forma, aunque Manuel de Jesús y Ricardo contaban con una limitada fortuna, en el fondo, podían comprender que le servían a un «propósito mayor», como lo era el sostenimiento de su apellido como una élite que debía tornarse hegemónica; proyecto al que aportaron una gran riqueza simbólica y que permitió encumbrar a Lico Jiménez y sus hijos.

\section{El Jiménez que alcanzó la cúspide}

El destacado politólogo Fabrice Lehoucq señaló que la historiografía en torno a la década de 1940 se había centrado en exceso en las figuras de Figueres Ferrer y Calderón Guardia, mientras que se relegaron a otros como Ulate, Cortés y, especialmente, a Jiménez Ortiz. ${ }^{34}$ Manuel Francisco «Lico» Jiménez Ortiz (1882-1952) se destacó, al igual que su padre, como un abogado, ahora josefino, puesto que se trasladó al centro de la capital. Desde su mansión Art Nouveau, fue partícipe de algunas de las decisiones más trascendentales de la época. Similar a sus antecesores, las alabanzas acompañaron su carrera: «[...] su talento preclaro, su actividad sin desmayos, su espíritu investigador y al día, el

31 Manuel Porras, El historiador Manuel de Jesús Jiménez Oreamuno. Mis libros con notas, 10 abril de 2016, párrafos 1 y 2, http://mislibrosconnotas.blogspot.com/2016/04/el-historiador-manuel-de-jesus-jimenez.html.

32 Iván Molina Jiménez, «Espías visibles, sorpresas esperadas y tiros sin puntería. El golpe de Guardia de 1870», Anuario de Estudios Centroamericanos, 20 (1994): 156, https://revistas.ucr.ac.cr/index.php/anuario/article/view/3229; Víctor Guardia, Memorias del general don Víctor Guardia (San José, Costa Rica: sin editorial, sin año), 36.

33 Una forma aplicada del concepto del político y el intelectual, que describió Max Weber, tal vez se podría reinterpretar como el político y el empresario. Como dato anexo, esta misma lógica pareciera aplicarse al expresidente de la República, Óscar Arias Sánchez, el cual fungía como político, mientras que su hermano Rodrigo, cumplía el rol de empresario y hasta de intelectual, pues había sido el estratega detrás de gran parte de las políticas y líneas seguidas por Óscar.

34 Marc Edelman, Fabrice Lehoucq, Steven Palmer e Iván Molina Jiménez, Ciencia social en Costa Rica. Experiencias de vida e investigación (Heredia, Costa Rica: EUNA, 1998). 
generoso desinterés que lo distingue». ${ }^{35}$ Estas sencillas palabras bien podían ser consideradas como el gesto amable de un genuino amigo; en cambio, los textos escritos tras su fallecimiento rayaban en la santificación:

El Lic. Manuel Francisco Jiménez Ortiz es uno de los arquitectos más eximios del despliegue nacional de los últimos tiempos. El ideal máximo en su vivir, lo hubo constituido el mejoramiento integral del país... De sus progenitores recibió la herencia de la honestidad que fuera patrimonio común en los hogares de abolengo de la antigua metrópoli. ...era considerado el idóneo para unir a la familia costarricense en tiempos aciagos... defensor de la democracia y la libertad jurídica en la Conferencia de la Paz en Buenos Aires, 1936... ${ }^{36}$

Honestidad, abolengo, estadista... estas eran las palabras que describían al que fuera el líder de la familia, el cual la llevó a su sitio como élite de poder. Al igual que había ocurrido con su padre Manuel Vicente, Lico era ávido para aliarse con las fuerzas dominantes, por eso, en 1917 figuraba como uno de los hombres de confianza del dictador Federico Tinoco Granados, a tal grado que se desempeñó como secretario de Hacienda y revirtió los intentos de Alfredo González Flores por establecer impuestos de la renta que afectaran a la clase dominante. Su amistad iba más allá, en 1919, Jiménez era dueño del diario $L a$ Información, vocero oficial de la dictadura, aunque en junio de ese año, una muchedumbre enardecida por los excesos del régimen, le prendió fuego. Pocas semanas después, el gobierno lo indemnizó; otro dato llamativo es que entre los descontentos ciudadanos se encontraba Carlos María Jiménez, hermano mayor de Lico; nuevamente, relucían las diferencias al interior de la familia. ${ }^{37}$

En los siguientes años - 1930 - y como ya fue citado anteriormente, Lico fungió como líder de los grandes cafetaleros y fundador de la Oficina de Defensa del Café — hoy ICAFE - ${ }^{38}$ y, en la década de 1940, fue uno de los grandes opositores al calderonismo y sus reformas. Más tarde combatió con fuerza a Rodrigo Facio Brenes y su intento de establecer una nueva constitución en 1949; a la postre, Lico ganó la partida y la vieja Carta Magna de 1871 se mantuvo con algunos cambios. Cabe recordar que, entre los redactores de esta, se encontraba su padre, por lo que era un deber familiar defender la vieja ley.

35 «El viaje de nuestro directo Lic. Don Manuel Francisco Jiménez Ortiz», Revista del Instituto de Defensa del Café de Costa Rica, n. ${ }^{\circ}$ 5-6, tomo I (marzo-abril, 1935): 464.

36 Alejandro Aguilar Machado, El licenciado Manuel Fco. Jiménez Ortiz (San José, Costa Rica: Trejos Hermanos, 1955), 5, 6 y 12. Por otra parte, cabría preguntarse hasta qué punto llegó la imagen de Manuel Francisco fuera de los círculos de la élite, ¿fue un personaje popular o reconocido como Ricardo Jiménez o su nombre era casi desconocido? Respuestas que otras investigaciones afines podrían atender.

37 Eduardo Oconitrillo, Los grandes perdedores. Dieciocho políticos costarricenses (San José, Costa Rica: Editorial Costa Rica, 2000), 177.

38 Años después su labor fue elogiada en una publicación oficial de la organización: Revista del Instituto de Defensa del Café de Costa Rica, n. ${ }^{\circ}$ 107-108, tomo XIII (setiembre-octubre, 1943): 556. 
Manuel Francisco fue un ávido colaborador en el reforzamiento de los imaginarios de su clan. Aparte de sus valores de hombre sabio y probo, destacaba en otros campos, característicos de la élite. Su mansión Art Nouveau -véase imagen adjunta - que se mantiene en pie, es única en Costa Rica y diseñada por Francesco Tenca Pedrazzini (1861-1908), quien estudió en la Academia de Bellas Artes de Milán. ${ }^{39}$ Otra práctica que con Lico se podría considerar como institucionalizada fue el matrimonio con pares socioeconómicos. De esta forma, en 1903 contrajo nupcias con Isabel de la Guardia, cuyo padre había colaborado con negocios de los Jiménez y que representaba a la élite panameña. Hasta el presente - más adelante se ofrecen ejemplos adicionales-, esta constituye una piedra medular de su poderío: suelen casarse con damas de la clase alta local o foránea, preferiblemente, hijas de sus principales socios; nuevamente, se evitan particiones y, más bien, se abre la posibilidad de absorber los patrimonios de otras élites.

Imagen 1. Casa Jiménez de la Guardia

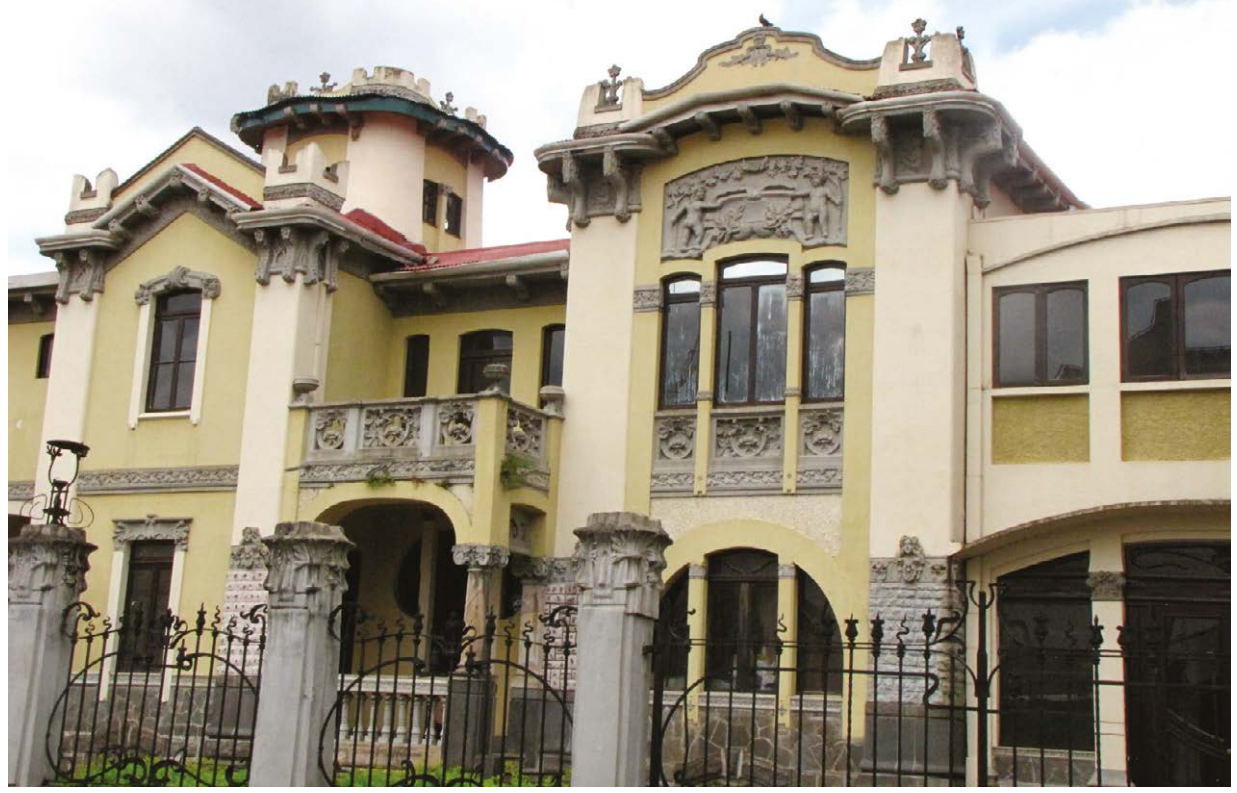

Fuente: Colección personal de fotografías de Lorna Marchena Sanabria (setiembre, 2019).

39 La casa se ubica en calle 5, entre las avenidas 1 y 3. Actualmente se le conoce como Casa de la Familia Jiménez de la Guardia y es propiedad de Maroy S.A. En 1998, fue declarada patrimonio histórico-arquitectónico. Poder Ejecutivo de la República de Costa Rica, Decreto Ejecutivo N. 27488 (San José, Costa Rica: Presidencia de la República y Ministerio de Cultura, Juventud y Deportes, 2 de noviembre de 1998). 
En el campo de la socialización, Lico fue ávido participante del más importante club josefino, en 1925, junto con Óscar Rohrmoser Carranza - miembro de uno de los clanes cafetaleros más importantes del periodo-y otros empresarios o profesionales de primera línea, fundaron el Club Unión, situado al frente de la Oficina de Correos y Telégrafos. El selecto club seguía las pautas de sofisticación y modas inglesas, el patio principal ofrecía un cuarteto de bellísimas estatuas de mármol, cortesía de Jiménez Ortiz. ${ }^{40}$ Pocos años después, se afirmaría que en estos salones suntuarios se escogía a los presidentes de la República, leyenda que perduró a lo largo del siglo XX.

A su muerte, su amigo y compañero diputado, Fabio Baudrit, le dedicó palabras que elevaron a Manuel Francisco al Olimpo:

Si hemos de creer en el carácter como determinante de la orientación humana, el señor Jiménez Ortiz — guardadas las distancias - acarició un ideal enorme de trascendencia, el mismo que anida la grandeza de señalados próceres americanos y empuja la actual conjunción mundial de fraternidad y de defensa.... ${ }^{41}$

Inclusive, Lico fue considerado como uno de los candidatos más idóneos para zanjar las diferencias entre Rafael Ángel Calderón Guardia y el periodista Otilio Ulate Blanco y evitar la guerra civil en 1948; pero la propuesta no fructificó. Tras su fallecimiento y las apologías ya mencionadas, la figura de Lico se desvaneció: ¿fue un infortunio de la historiografía contemporánea que rechazaba a los «grandes personajes»? ¿Un trágico ensañamiento del destino con un hombre tan relevante? Ninguna de las dos opciones, a partir de su deceso, la familia podría haber auspiciado un conveniente olvido, maximizando las figuras de Jesús y Ricardo Jiménez, mientras que ocultaba a su líder más destacado. ¿Por qué? Es muy simple, en el imaginario que las élites han construido desde el siglo XIX y con ciertas modificaciones en el XX, Costa Rica es el crisol de la democracia representativa: desmanteló el ejército, amplió el voto hasta establecerlo universal, directo y secreto; goza de una impecable institucionalidad y después de 1950, creció la clase media, y disminuyeron las desigualdades económicas; ${ }^{42}$ este discurso ha llegado al extremo de señalar que 1948 fue la fecha del deceso de la denominada «oligarquía cafetalera», de la que Lico era parte central. ${ }^{43}$

40 Andrés Fernández, «Un edificio del Club Unión, entre dos incendios», La Nación, 22 de noviembre de 2015, http://www.nacion.com/ocio/artes/incendios_0_1525847425.html.

41 Fabio Baudrit, «Manuel Francisco Jiménez Ortiz», La Nación, 22 de abril de 1952, 4.

42 Para profundizar en estos temas del imaginario se pueden consultar los textos: Manuel Calderón Hernández, Elementos del imaginario en la Costa Rica precafetalera. Cuadernos de Historia de las Instituciones de Costa Rica, vol. 25 (San José, Costa Rica: EUCR, 2015). Alexander Jiménez Matarrita, El imposible país de los filósofos (San José, Costa Rica: EUCR, 2008).

43 A tal extremo, que Samuel Stone afirmó que la victoria de Figueres y sus compañeros, equivalió al punto final de la oligarquía. Samuel Stone, La dinastía de los conquistadores (San José, Costa Rica: EDUCA, 1982), 315 . 
Aunque ocultar a Lico es una afrenta al orgullo de la familia, es un mal necesario para preservar su patrimonio. Su invisibilización permite reforzar el mito de una Costa Rica igualitaria donde las élites son pequeñas, bonachonas - como Ricardo Jiménez, José Figueres Ferrer o Abel Pacheco-y la concentración de fortunas es un mero disparate. Esto, por supuesto, facilita el control social, mantiene un juego electoral más superficial y evade cuestionamientos profundos en temas fiscales y de la redistribución de la riqueza. En conclusión, Manuel Francisco desapareció, para que la familia se mantuviera más fuerte y segura en su posición hegemónica.

\section{Cuando una élite quiere forjar candidatos}

Tras el fallecimiento de Lico Jiménez, su hijo, Manuel Jiménez de la Guardia (1908-1994), ascendió al poder o, más bien, al liderazgo de la familia, siguiendo los preceptos de sus ancestros. Primero, lo más evidente, se reiteraba el nombre de Manuel; segundo, al igual que sus dos predecesores, también estudió derecho, aunque ejerció más en beneficio de sus empresas; tercero, contrajo matrimonio con Flora Borbón Castro, hermana de los socios de su padre. Sin embargo, su vida pública fue más reservada y, aunque se le calificó como uno de los hombres más influyentes de Costa Rica: «Estadista y empresario costarricense, de reconocida e intachable rectitud, de notable influencia en el desarrollo económico del país durante los últimos años». ${ }^{44}$, fue considerado como un hombre tímido y de bajo perfil mediático. ${ }^{45}$

Si fue tímido o con una capacidad de oratoria limitada, es en verdad irrelevante. ${ }^{46}$ La situación de su clan había cambiado, debido, sobre todo, a las nuevas industrias que lideraban. Entre 1942 y 1949, Lico Jiménez había obtenido el control - como accionista de peso- de FIFCO, el diario La Nación y la Hacienda Juan Viñas y contó, en la mayoría de casos, con el apoyo de las familias Steinvorth, Mendiola, Borbón, entre otras. ${ }^{47}$ Jiménez de la Guardia tuvo la responsabilidad de liderarlas y, en los años sesenta, este imperio económico se expandió mucho más, solo la cervecería se modernizó con tecnología de punta hasta convertirse en una de las más avanzadas del istmo centroamericano, mientras la cantidad de subsidiarias - que le permitieron convertirse en un monopolio- crecía día con día.

44 Marta Castegnaro, «Día histórico. Manuel Jiménez de la Guardia», La Nación, 25 de setiembre de 1987, 17B.

45 José Luis Mora, «Forjadores de sueños», Actualidad Económica Cámara de Comercio de Costa Rica, vol. 10, n. $^{\circ} 8$ (1995): 64.

46 Cabe anotar que de la Guardia fue ministro de Industrias de José Joaquín Trejos entre 1966 y 1969, en este puesto, impulsó el polémico proyecto de ALCOA; se retiró para atender sus negocios antes que explotaran las protestas.

47 Parte de esta adquisición fue descrita por Rafael Jiménez, Juan Viñas dentro del contexto histórico nacional (Heredia, Costa Rica: Departamento de Publicaciones de la Universidad Nacional, 1992) y en Porras Jara, Los primeros cien años de la Florica Ice \& Farm... 
Simplemente, Jiménez no podía fungir como político y empresario a la vez, era una labor no solo titánica, sino riesgosa, se exponía al escrutinio público y podía perjudicar sus preciadas inversiones. En consecuencia, paulatinamente la familia desarrolló nuevos mecanismos para incidir en la política a través de candidatos testaferros, protegidos o, si se quiere, ungidos. No obstante, esto no implicó resultados inmediatos ni positivos; en muchas ocasiones, la frustración fue la recompensa de Jiménez.

Desde la década de 1940, Manuel era un activo colaborador - y socio- de su padre; años más tarde, gracias al renombre de Lico y el prestigio de sus parientes, como Manuel de Jesús y Ricardo Jiménez Oreamuno, de la Guardia era un hombre probo, una figura de peso en la política costarricense. Incluso, en 1966 trató de mediar ante Daniel Oduber Quirós para que se diera la concordia entre el gobierno de Trejos Fernández y el Partido Liberación Nacional. ${ }^{48}$ Afirmar que las viejas élites - «oligarcas», conservadoras o liberales- estaban al borde de la extinción, sería una mera hipérbole y una afirmación insostenible, por no decir imaginaria. La situación que enfrentaba Jiménez era compleja, en esencia, había heredado una parte del liderazgo de la clase dominante, pero esta se encontraba muy fraccionada y renuente a lograr consensos; el enemigo no solo se encontraba en el PLN y el Estado interventor, sino en sus filas divididas y mezquinas.

Durante el último gobierno de Figueres Ferrer de 1970 a 1974, Jiménez de la Guardia pudo celebrar que su hijo mayor, Manuel Jiménez Borbón y su medio-hermano, Guillermo Jiménez Ramírez - actor social de un aparente bajo perfil-, se convirtieran en diputados que representaron al Partido Unificación Nacional. Fue una satisfacción efímera. A pesar de que el joven Manuel se esmeró en cuestionar al Estado interventor y los gastos en las instituciones autónomas, ${ }^{49}$ sus habilidades como político eran, por lo menos, mediocres. Figuras rivales, como Ángel Edmundo Solano Calderón - exministro de Seguridad y exdirector de RECOPE—, se referían a Manuel en los términos de que «su único valor es ser hijo de papá $\aleph^{50}$, los amigos más cercanos lo trataron de defender, pero era un secreto a voces: el patriarca era de la Guardia y tanto él, como sus hijos, carecían de las brillantes aptitudes y retórica de Lico Jiménez.

De nuevo, la alternativa viable parecía encontrarse en obtener un delegado y la figura idónea parecía ser el influyente médico, Fernando Trejos Escalante, primo hermano del expresidente José Joaquín Trejos y uno de los máximos líderes de la Asociación Nacional de Fomento Económico (ANFE), el centro ideológico que impulsó lo que se llegaría a conocer como el neoliberalismo costarricense. En enero de 1973, Trejos Escalante fue ratificado como candidato

48 Rafael Valenzuela, «El arte de gobernar», La Nación, 8 de noviembre de 1966, 8.

49 «Nómina de candidatos a diputados en todo el país», La Nación, 8 de enero de 1970, 29 y «Presidencia de la República no ha violado ninguna ley», La Nación, 23 de julio de 1971, 1 y 74.

50 «Una muestra de valor constante», La Nación, 16 de noviembre de 1973, 4A. 
presidencial, tras una reñida convención nacional, acompañado por Jorge Borbón Castro - cuñado de Jiménez de la Guardia - y Longino Soto Pacheco como vicepresidentes. Fernando garantizó que se habían abandonado los vicios de «conciliábulos o mediante acuerdo de los dirigentes o mediante convenciones en que solo participaran los que pertenecen a la maquinaria de un partido...». ${ }^{51} \mathrm{Se}$ contaba con el apoyo de viejos y futuros líderes políticos como Francisco Calderón Guardia y de los jóvenes Miguel Ángel Rodríguez Echeverría y Rolando Laclé Castro; otras figuras en cambio, perseguían sus propias agendas, como Guillermo Malavassi Vargas, Óscar Barahona Streber y Rodrigo Carazo Odio - otrora liberacionista - A pesar de las divisiones, se unificaron bajo el nombre de Alianza Nacional Cristiana o Gran Coalición.

Para calmar los ánimos y asegurar alianzas, Manuel Jiménez de la Guardia, junto con el exvicepresidente de la República, Alberto Oreamuno Flores, los políticos Fernando Lara Bustamente y Julio Suñol Leal, formaron una Comisión de Notables que se supondría, lograría dirimir las asperezas de la derecha:

Don Manuel Jiménez de la Guardia convocó a representantes de los tres partidos y del grupo Alianza de don José Joaquín[...], a una reunión en su casa. En esa reunión tampoco hubo acuerdo ni cambio alguno debido a la negativa a aceptar que Fernando Trejos tenía una posición diferente, porque era el único verdadero candidato, electo en una convención y porque era quien mayor apoyo popular tenía, según todos los cálculos hasta entonces. ${ }^{52}$

El grupo era demasiado heterogéneo, Rodrigo Carazo Odio era un socialdemócrata convencido, separado del PLN por rencillas con Figueres; mientras que Rodríguez, Malavassi y otros eran afines al neoliberalismo y, por último, el mismo Trejos Fernández le retiró el apoyo a su primo, lo que favoreció su caída ante Daniel Oduber. Era una derrota pasajera para Jiménez de la Guardia, pero este no se rindió. En 1975, se había convertido en el presidente ejecutivo del Partido Unión Popular y que luego, tras una fusión con otras agrupaciones de la derecha, llevaría a la Presidencia a Carazo en 1978 y un año más tarde, Jiménez aparecía como presidente de la Unidad. ${ }^{53}$ Lo más curioso es que Manuel fue el gestor del proyecto de ALCOA una década atrás y su principal rival había sido Carazo. De nuevo, eran las viejas tradiciones que habían empleado sus antecesores, los Jiménez se unían al bloque dominante o al político que pareciera más conveniente a sus intereses. ${ }^{54}$

51 Grettel López y Reinaldo Herrera (eds.), Ensayos en honor a Fernando Trejos Escalante (San José, Costa Rica: Academia de Centroamérica y ANFE, 2004), 53.

52 Ibíd., 26 y 72.

53 Omar Gálvez, «Propondrán reducir en tiempo y en dinero campaña electoral», La Nación, 28 de mayo de 1975, 10A; «Aprobado proyecto que salva actividad azucarera del país», La República, 14 de setiembre de 1979, 3.

54 En 1949, Figueres Ferrer nombró a Jiménez de la Guardia, como parte de la Junta Directiva del Banco Nacional, pero este renunció rápidamente. En esta ocasión, la familia parecía no apreciar al victorioso caudillo, prefirieron una oposición más directa. Manuel Solís Avendaño, La institucionalidad ajena. Los años cuarenta y el fin de siglo (San José: EUCR, 2006), 442. 
Cuando se realiza el balance, el proyecto de influir políticamente de Jiménez de la Guardia resultó bastante decepcionante: su hijo mayor contó con escasa potencia —aunque, con mayores éxitos a cargo del diario La Nación —, no logró coronar a Fernando Trejos, a pesar de las reuniones en su propia mansión y aunque obtuvo una victoria con Carazo, su gobierno se mostró ambivalente y reacio a seguir los consejos - $\mathrm{u}$ órdenes - de las élites conservadoras. A pesar de este fracaso, la familia acogió la iniciativa y, años después, se intensificó la práctica de recurrir a testaferros.

\section{La cultura de una élite empresarial costarricense en la segunda mi- tad del siglo $\mathrm{XX}$}

A mediados del siglo XX es cuando se ha logrado recopilar una mayor imagen de la cultura y prácticas contemporáneas de la familia Jiménez. Manuel Jiménez Borbón, el primogénito de Jiménez de la Guardia, nació en 1935 y falleció en 1990. Estudió derecho en la Universidad de Costa Rica y periodismo en la Universidad Autónoma de Centro América (UACA). ${ }^{55}$ Como ya fue mencionado, fungió como diputado en el periodo 1970-1974, pero su actuar pasó casi inadvertido, mejor suerte tuvo como directivo de La Nación, puesto en que fue sucedido por su hijo, Manuel Jiménez Echeverría. Si bien, ambos han tenido una participación sustancial en las empresas familiares, se repite la tendencia señalada para Jesús y Ricardo Jiménez décadas atrás: parecieran encontrarse supeditados a la «línea principal», en especial Echeverría, que sigue los designios trazados por su tío, Rodolfo Jiménez Borbón, el actual patriarca de facto.

Rodolfo, nacido en 1938, es una muestra de los cambios y permanencias de los valores más apreciados por la familia. Entre las continuidades que refleja, se casó con Olga Solera Fernández en 1959, hija de Jaime Solera Bennett (19171995), socio de su padre en el Grupo Nación. ${ }^{56}$ Igualmente, sus hijos recibieron el nombre tradicional: Jaime Manuel y Rodolfo Manuel. Mientras que la hermana del líder familiar, Flora, contrajo matrimonio con el empresario Guillermo González Truque —un socio contemporáneo- y los hijos de estos, Carlos y Armando González Jiménez, parecen seguir las directrices de su tío; Carlos en particular, fue viceministro de Hacienda de Abel Pacheco de la Espriella (20022006), cargo que fue facilitado por la alianza Pacheco/Jiménez que más adelante se retomará. Entre los elementos novedosos que se pueden citar, Rodolfo y sus hijos poseen una formación en administración de empresas y sendos lazos con el Instituto Centroamericano de Administración de Empresas (INCAE); mientras que se abandonó la profesión tradicional de abogacía. ${ }^{57}$

55 «Periodismo de luto», La República, 31 de octubre de 1990, 2 A.

56 José Luis Mora, 63.

57 «INCAE: sinónimo de preparación solvente en materia de administración de empresas», La Nación, 11 de setiembre de 1970, 46. Además, esta entidad se encuentra vinculada a la Universidad de Harvard y frecuentemente, brinda asesorías profesionales a la FIFCO. 
En cuanto a otras prácticas que se mantenían sin mayores modificaciones, se pueden citar las bodas. Dada su cercanía con el credo católico, el grueso de miembros de la familia debe profesar este credo y las ceremonias matrimoniales son acordes; en la década de 1950 estas eran celebradas en la iglesia de Santa Teresita, ubicada en el noreste de la ciudad de San José y, en muchas ocasiones, eran oficiadas por clérigos emparentados con los Jiménez. Asimismo, las notas sociales, incluyendo la fotografía de la joven novia, aparecían en el diario La Nación, junto con múltiples detalles de su vida privada, se sumaban, por supuesto, sendas apologías. Las listas de invitados rebosaban de miembros de las familias de élite, con apellidos como Dent, Guardia, Montealegre, Tattembach, Iglesias, entre otros y la subsecuente fiesta, tenía lugar en el Gran Hotel Costa Rica, inmueble que también era propiedad del clan. ${ }^{58}$

Con todo orgullo, en diciembre de 1959 se anunció la boda de Rodolfo Jiménez y Olga Solera, la nota del periódico no escatimó en elogios:

[...] constituyendo su boda uno de los más brillantes sucesos sociales, por los relevantes méritos de ambos contrayentes, fundándose así un hogar que será gala y prestigio de la sociedad costarricense. [...] El novio es un caballero a carta cabal, culto y talentoso, de noble corazón y clara inteligencia, atributos heredados de los suyos y de los que ha sabido hacerse digno. ${ }^{59}$

De nuevo, se aprovechaba la oportunidad para magnificar al novio, con epítetos como culto, inteligente, linaje... En los años siguientes, el mismo medio de comunicación, se encargó de dar detalles acerca de la vida social de la pareja, denotaba su excelencia en el golf — deporte de por sí elitesco - y más adelante, su apoyo a las artes. Por ejemplo, en el año 2000 auspiciaron al escultor costarricense, Jorge Jiménez Deredia, para que colocara una de sus obras en la Basílica de San Pedro. ${ }^{60}$

Otro aspecto en que la familia ha participado activamente es en organizaciones o iniciativas de caridad. Esta es una práctica común en las élites y en el caso de los Jiménez es de larga data. Más importante, es uno de los pocos espacios públicos donde se destacan las mujeres del clan. En 1944, la Junta de Caridad de San José presumía del apoyo de los Keith, Cervantes, Escalante, Montealegre, Rohrmoser, Trejos y Jiménez. Ivonne Clay — primera esposa de Calderón Guardia - y María Eugenia Jiménez de la Guardia — hermana de Manuel — eran las principales impulsoras de un asilo para ciegos. ${ }^{61}$ Para 1958, nuevamente otra

58 «La distinguida boda Castro-Jiménez», La Nación, 20 de diciembre de 1957, 30. El hotel había sido fundado en 1930 por Luis Paulino Jiménez Ortiz, hermano de Lico.

59 «La distinguida boda de hoy Jiménez-Solera», La Nación, 16 de diciembre de 1959, 44.

60 «Final del torneo de apertura a 36 hoyos, estilo medal pley termina con el brillante triunfo de Rodolfo Jiménez Borbón», La Nación, 25 de abril de 1960, 24. Aurelia Dobles, «Filmar el soplo creador», La Nación, 17 de setiembre de 2000, http://wvw.nacion.com/ancora/2000/septiembre/17/ancora1.html.

61 Manuel Solís Avendaño, «La élite caritativa y la institución psiquiátrica: una lectura desde los años cuarenta», Revista de Historia, n. $^{\circ}$ 53-54 (enero-diciembre, 2006): 124-125. 
gran dama era reconocida como ejemplo de buenas obras, en este caso, para apoyar la construcción de viviendas destinadas a los sectores más desfavorecidos, la receptora de admiración era Isabel de la Guardia, viuda de Lico:

\begin{abstract}
De ella, de su recordado esposo don Lico, y de sus estimables hijos, algunas gentes sabíamos, en ese aspecto de la vida de los seres humanos, muchas anécdotas, exactos, por cierto, que nos los describían como virtuosos de la generosidad. Silenciosamente, para no lesionar nunca su habitual modestia, hacían y practicaban el bien de la manera que lo entendieran. Jamás les importó medir o pesar la opinión de los demás respecto de los actos privados de su magnífica existencia. ${ }^{62}$
\end{abstract}

Modesta, virtuosa, imagnifica!, la diferencia es que estos halagos eran conferidos a una señora de los Jiménez. Ahora, en párrafos precedentes se anotaba que las mujeres de esta élite contaban con pocos espacios fuera de la vida privada. Inclusive, se podría argumentar que el grueso de matrimonios pareciese convenido por sus padres, práctica rastreable hasta el siglo XIX — io desde la Colonia?- . Ana de Miguel precisa que las mujeres occidentales han sido víctimas de una nociva invisibilización, también de una absorción, puesto que sus apellidos se borran y son integradas a la familia de su esposo. Por eso, cuando se habla de Jiménez, se debe tener claro que detrás se hallan muchas otras piezas de la élite, como los Coronado, Oreamuno, de la Guardia, Montealegre, Solera, entre otros. Ahora, la participación femenina ha sido vital, Ramona Jiménez Zamora - hija de Jiménez Robredo- realizó las incursiones que permitieron apropiarse de varios terrenos en la región del Reventazón-Turrialba en la década de 1850 y que luego fue imitada por otros de sus parientes. ${ }^{63}$ En años más recientes, Ileana Jiménez Montealegre, prima de Rodolfo, ha tenido una participación como concejal suplente de la Municipalidad de Curridabat, cargo que obtuvo a través del Partido Curridabat Siglo XXI, del cual su parentela ha sido gran donante. ${ }^{64} \mathrm{Al}$ igual que sus congéneres varones, las mujeres les sirven a los intereses de la familia, son fundamentales en los mecanismos utilizados para sellar alianzas y concentrar la riqueza.

Un último ejemplo de obra filantrópica y referida a Manuel y su hijo Rodolfo se encuentra en la comunidad de El Cacao en Alajuela, contiguo a una finca que poseían desde el decenio de 1930. Entre 1976 y 1978, los propietarios autorizaron la construcción de un tanque de almacenamiento de agua que luego fue transferido a la Municipalidad de Alajuela. En 1983, Manuel respondió

62 Ricardo Toledo, «El gesto de una dama», La Nación, 24 de abril de 1958, 31.

63 Joaquín Fernández Montúfar, Historia ferrovial de Costa Rica (San José, Costa Rica: Galería del progreso nacional, 1934), 103.

64 Más de nueve millones de colones, aportados por ella, su hermano Ricardo Adolfo, Rodolfo y su esposo, el también empresario inmobiliario, Fernando Terán Alvarado. Tribunal Supremo de Elecciones, Contribuciones a los Partidos Políticos-C.SXXI. Periodo electoral 2006-2010 (San José, Costa Rica: TSE, febrero de 2010), folios 2-7. 
afirmativamente a un llamado de la comunidad para que se construyera un Centro Cívico, complejo que incluía un salón multiusos, oficina policial y una pequeña clínica; este inmueble tardó casi veinte años en ser donado por completo, pues el proceso arrancó en 1986 y se completó hasta el 2005; este fue bautizado en honor a Jiménez de la Guardia y su apreciado gesto. ${ }^{65}$

El altruismo de la familia no debe prestarse para interpretaciones extremas. Por un lado, sus obras no denotan un compromiso social profundo, las élites pretenden encargarse de la cuestión social desde su perspectiva personal afín a dar meras limosnas y convertirse en «buenos cristianos», inclusive, con un cierto afán de reemplazar al Estado; también, suele ser problemática la definición de pobreza que de fondo se ofrece: ¿cómo se origina?, ¿qué papel juega su riqueza? Por otra parte, en muchos casos están autoconvencidos de su generosidad y se identifican como padres de la patria, que deben velar por la ciudadanía e impulsar el desarrollo nacional; estos discursos se pueden deducir a partir de todo el material detallado anteriormente.

Otros aportes destacables provienen del valioso estudio del sociólogo Jeffery Paige, enfocado en los grandes cafetaleros centroamericanos de los años ochenta del siglo pasado. Sus hallazgos no dejan de sorprender y entre sus informantes, para el caso costarricense, se encontraba Rodolfo Jiménez. Destacaba que la cultura política y los estereotipos entre las élites del istmo eran muy similares, mientras que las diferencias eran realmente superficiales. Los potentados del café costarricense mantenían los mitos raciales blancos, así como los imaginarios de la democracia rural, es decir, una Costa Rica de campesinos pobres, igualitarios y exentos de mayores conflictos internos. Algunos de los informantes de Paige afirmaron sin tapujos que la estabilidad del país se debía a su fuerte herencia «europea blanca»e insinuaban la inferioridad racial de los pueblos autóctonos.

Mientras buscaban argumentos para demostrar el buen dominio que habían ejercido en Costa Rica como «oligarcas benignos», no perdían oportunidad en expresar sus prejuicios contra el resto del istmo; en este caso, tildaban a las élites salvadoreñas como excesivamente avariciosas, violentas y hasta esclavistas. Al contrario, defendían una visión de sí mismos como una clase dominante benigna, que propició la redistribución de la riqueza y que, por ello, no se daban las desigualdades imperantes en la mayor parte de América Latina. Inclusive, se mostraban convencidas de que, a partir de 1930, se había apagado el poder de los grandes beneficiadores-exportadores y para 1948, la extinción se completó. ${ }^{66}$ Esta información recopilada por Paige es, sin duda, invaluable, si la misma élite cree fervorosamente que ella no es un grupo de poder y que,

65 Óscar Monge Alfaro, Historia del pueblo de Cacao de Alajuela (Alajuela, Costa Rica: documento inédito, 2009), 43 y 48.

66 Jeffery Paige, Coffee and Power. Revolution and the Rise of Democracy in Central America (Boston, Massachusetts: Harvard University Press, 1998), 222-232. 
además, favorece un desarrollo inclusivo nacional, su identidad y cultura política se torna más compleja.

En su afán por controlar Costa Rica, la élite de poder procedió al paso más importante: autoadoctrinarse y defender tajantemente un discurso de paz social e igualdad. Cuando sumamos sus valores cristianos, caritativos, paternalistas, homogeneizantes, de respeto a la autoridad, así como su influencia política o mediática, es fácil explicar que muchas de sus estrategias y "proyecto país» se encuentran ancladas a estos valores, los cuales en el fondo poseen fuertes componentes coloniales y decimonónicos. Tomando en cuenta estos puntos, se puede comprender con mayor precisión el episodio siguiente y final, en el que Rodolfo Jiménez logró elegir presidentes.

\section{Rifas y cuentas fantasmas: el impulso de candidaturas}

Es un tema para un intenso debate: ¿hasta qué punto los Jiménez han sido decisivos en las políticas implementadas en las últimas cuatro décadas? Sin lugar a dudas y a pesar de sus tropiezos, su influencia no se puede descartar. Fueron decisivos en la concreción de la Unidad que llevaría a la presidencia a Rodrigo Carazo Odio en 1978 y, a partir de ese momento, se han aliado estrechamente con los principales actores políticos para la promoción de sus agendas, afines al libre comercio y otras perspectivas neoconservadoras. A finales del siglo XX, se habían consolidado como una familia modernizante, que impulsaba la transnacionalización de la Florida Ice and Farm Company (FIFCO), así como expandían sus negocios a otros rubros, tales como inmobiliarias, turismo, banca privada y se convirtieron en protagonistas estrellas de la bolsa de valores locales. Es fácil confundir la senda que Costa Rica ha seguido con el desarrollo reciente de la familia. No obstante, era una familia moderna, con sólidas bases afines al Antiguo Régimen, especialmente en lo que respecta a su proyecto de elegir presidentes. Si ya antes habían aconsejado a candidatos o les habían dado su incondicional apoyo, ahora querían ser el factor crucial en su elección y financiamiento.

En agosto de 2003, el magnate cervecero Rodolfo Jiménez Borbón fue llamado a comparecer ante una comisión legislativa que investigaba los extraños financiamientos de la campaña electoral anterior, especialmente referida a los dineros que recibió el eventual ganador, Abel Pacheco de la Espriella (20022006). En la cita, que por mucho se podría considerar estrafalaria, Jiménez dio a conocer detalles excéntricos del funcionamiento de las élites y también, de la política costarricense. El punto de partida fue el fallido intento de reactivar la reelección presidencial, medida que a la postre benefició a Oscar Arias Sánchez en 2006. El mismo Arias relató los pormenores de este proceso:

La primera vez que se me envió un mensaje fue cuando mi hermano Rodrigo, junto a - el empresario - don Rodolfo Jiménez, visitaron al presidente de la República, 
Miguel Ángel Rodríguez, en la Casa Presidencial, para hablar de otro tema y don Rodolfo introdujo el de la reelección.

Don Miguel Ángel le dijo a mi hermano: «nada me gustaría más que poderle pasar la banda presidencial a Óscar y nada me convence después de un año de gobierno y las dificultades que he tenido para aprobar legislación importante que luchar por la reelección presidencial».

Eso llevó a don Rodolfo Jiménez a invitarnos a los expresidentes José María Figueres, a Rafael Ángel Calderón y a mí a una reunión con mi hermano y con don Rolando Laclé, y hemos tenido muchas reuniones. Hemos desayunado muchas veces en la casa de don Rolando Laclé, donde don Rodolfo Jiménez, donde don Miguel Ángel, para hablar de este tema. ${ }^{67}$

El plan consistía en que Arias fuera reelecto en 2002 gracias a su popularidad, la cual era destacada por encuestas publicadas en el diario La Nación, de los Jiménez:

La cualidad más importante que se le atribuye a Arias es ser el exjefe de Gobierno más inteligente. Así lo consideró la mitad —el 50,5 por ciento- de las personas entrevistadas. En segundo lugar, el 48,3 por ciento consideró que fue capaz de rodearse de un buen equipo de gobierno. Arias también acumuló una elevada puntuación en rubros como: siempre inspiró confianza - 46,3 por ciento-, tiene altos valores éticos-morales $-45,9$ por ciento - y posee ideas propias $-44,6$ por ciento-.${ }^{68}$

Con Arias en el poder, proyectos, como el CAFTA, podrían ser rápidamente aprobados y episodios bochornosos para la élite, como la derrota del «Combo del ICE» en el año 2000, que buscaba privatizar parte del área de telecomunicaciones, no se repetiría. Según los relatos de Arias, Jiménez y el excandidato presidencial del PLN, José Miguel Corrales Bolaños, todos los políticos citados en la reunión que tuvo lugar en la residencia del empresario cervecero estuvieron de acuerdo en apoyar tanto la reelección, como a la figura de Arias. Pronto, comenzarían las discrepancias, el consenso no era tan grande como se creía, Rodríguez Echeverría detalló:

[...] cuando don Óscar planteó la reelección y me invitó, don Rodolfo Jiménez, a su casa, en la inauguración de su casa, con don Óscar, con don Rafael Ángel, eh [...] y nos invitó a su oficina, en medio de la fiesta de inauguración de su casa, y entramos a la oficina y me plantea, que don Óscar quiere que se apruebe en el Congreso la reelección; yo le dije muy claramente: «yo, la verdad, no estoy muy de acuerdo con lo de la no-reelección[...] pero yo no puedo echar a perder mi Gobierno, metiéndome en una pelea política en la Asamblea para sacar ese principio». ${ }^{69}$

67 «Arias: me embarcaron», La Nación, 24 de mayo de 2000, http://wvw.nacion.com/ln_ee/2000/mayo/24/ pais $2 . h t m l$.

68 Ronald Matute, «Oscar Arias con fuerte imagen», La Nación, 29 de setiembre de 1998, http://wvw.nacion. com/ln_ee/1998/septiembre/29/pais1.html.

69 Claudio Alpízar, Noche sin tregua, entrevista a Miguel Ángel Rodriguez Echeverría (San José, Costa Rica, 24 enero 2013), minutos 53:04-54:21, https://www.youtube.com/watch?v=yTdoGloAiJU\&feature=share. 
Para febrero del año 2001, el proyecto se encontraba desecho, Corrales afirmaba que Calderón Fournier era uno de los que más adversaba las ambiciones de Arias:

\begin{abstract}
Se deshizo por razones obvias. Reflexionó Calderón Fournier y tuvo pánico, precisamente, ante las encuestas que fijaban un alto índice de popularidad del Premio Nobel, con el peligro de barrer al PUSC. He ahí el detalle. Y como don Rafael Ángel domina de pies a cabeza a su Partido, dio la orden de marcha atrás, de frenar la reelección, que se cumplió, ¡faltaba más.... $7^{70}$
\end{abstract}

Otras fuentes, señalan que muchos de los políticos liberacionistas tampoco apreciaban la iniciativa, pues se veían relegados de los comicios y caían ante la hegemonía de Arias Sánchez y sus aliados. A mediano plazo, sus temores no resultaron infundados, Corrales Bolaños, los hermanos Araya Monge y otros actores - como el mismo Álvarez Desanti ${ }^{71}$ - fueron relegados del partido y hasta la fecha no han alcanzado la Presidencia de la República. Volviendo con Jiménez Borbón, este enfrentaba retos similares a los de su padre en el año 1974, cuando sus consejos y reuniones eran burlados por sus pretendidos aliados. Pero, en esta ocasión, se habían aprendido las lecciones y el empresario tejió un plan para resguardar sus intereses y preferencias electorales.

Para ello, recurrió a la figura del médico psiquiatra, Abel Pacheco de la Espriella, quien incluso figuró entre los invasores calderonistas de 1955. Pacheco era una figura popular entre la ciudadanía, gracias a sus programas televisivos y su estilo cándido de política, muy similar al que empleara Ricardo Jiménez, más de medio siglo atrás. Sin embargo, Abel no contaba con el apoyo de las facciones y actores dominantes del Partido Unidad Social Cristiana; Calderón y Rodríguez no lo consideraban, ni de cerca, como un candidato idóneo.

A pesar de la oposición explícita del partido, Jiménez y otros miembros de la élite patrocinaron a Pacheco, creando una estructura partidaria paralela, que lo llevó - tras una segunda ronda electoral - a la victoria en 2002. Cuando acudió a la comparecencia en el Congreso, Rodolfo precisó los orígenes de los dineros invertidos:

De lo que pude reconstruir en estos días, que yo personalmente solicité a esas personas, la mayoría o todas son personas a quienes conozco. Me permito leerla: André Garnier y aquí quiero explicar algo, no vi los cheques, le pedí a don

70 José María Penabad, «Reelección empezó con el azúcar...», Ojo, 7 de febrero de 2001, 3.

71 Para la campaña electoral de 2018, Álvarez Desanti recibió un tímido apoyo por parte de Óscar Arias, aunque en última instancia, ni siquiera pudo avanzar a la segunda ronda electoral. Este caso, es por demás curioso, ya que Desanti es concuño de Manuel Francisco Jiménez Echeverría, presidente de la Junta Directiva del Grupo Nación y sobrino de Rodolfo. Manuel, junto con Desanti, fueron los que, supuestamente, invitaron a Johnny Araya Monge a renunciar a sus aspiraciones presidenciales en 2014. Álvaro Murillo, «PLN: tres años después del abandono de la campaña», Semanario Universidad, 28 de febrero de 2017, https://semanariouniversidad.com/pais/pln-tres-anos-despues-del-abandono-de-la-campana/. 
André copia de los recibos. André Garnier, diez mil dólares. Carlos Montealegre Quirós, varias contribuciones, me parece que tres y eso también se lo pregunté a él, veinticinco mil dólares. MULTIPLAZA del Este, veinte mil dólares. BANEX, veinticinco mil dólares. Huber Garnier, diez mil dólares. Max Acosta cuatro mil dólares. VICESA, veinticinco mil dólares. Alejandra de Robelo, yo tenía idea de que eran cinco, el periódico publica que son tres, no sé, no puedo decir si son tres o son cinco. Grupo Andrus, diez mil. Daniel de la Cruz, no tengo monto. Eduardo Uribe, no tengo monto. Digamos que esto es una muestra. ${ }^{72}$

Sobra decir que los montos donados correspondieron a cientos de millones de colones, más llamativo es que ni siquiera se llevaron anotaciones precisas de cuánto se recibió o, al menos, eso es lo que aparentaban. El listado anterior era vergonzoso, pues dejaba entrever una excesiva influencia del sector empresarial, no solo local, sino foráneo. Además, la cantidad de dinero derrochado en campañas, la creación de estructuras paralelas y la apertura de cuentas en Panamá, fuera de los controles del Tribunal Supremo de Elecciones (TSE), despertaban preocupación y dudas acerca del avance real del sistema democrático vigente. Como si estos donativos descontrolados no fueran suficiente problema, se sumaban los excéntricos mecanismos para obtenerlos, las que podríamos denominar como rifas de élite:

En particular - estoy haciendo memoria - me parece que el costo de esta rifa era de diez mil dólares. Tenía cuatro cupones, dos mil quinientos dólares cada cupón.

En el caso particular que me está preguntando, le vendí el número a don Wilhem [Steinvorth], era un número entero y él tuvo la suerte — ahora digo que la mala suerte- de haberse ganado esa rifa. ${ }^{73}$

Este tipo de rifas estaban prohibidas, eran potestad exclusiva de la Junta de Protección Social y estas, en particular, de miles de dólares, señalaban directamente que la elección de Pacheco fue sin lugar a dudas, una decisión de la clase alta o el empresariado; el cual, desesperado, recurrió a las formas más llamativas para recaudar fondos y colocar al médico psiquiatra en la Casa Presidencial. De todas formas, los diputados se mostraron excesivamente aduladores por la presencia de Jiménez, ya que se percibía que no querían indisponerlo ni insultar a un hombre que pertenecía a una de las familias patricias del país, por eso insistieron:

Es la primera vez que usted viene a un acto de esta naturaleza y yo le aseguro don Rodolfo, que la turbación, ofuscación o preocupación que pueda causarle será muy pasajera, y usted, sus amigos y su familia van a recordar con orgullo,

72 Asamblea Legislativa, Expediente $n .^{\circ}$ 15.0002. Acta de Sesión Ordinaria $n .^{\circ}$ 29, «Comisión especial investigadora del financiamiento de los partidos políticos y las donaciones que hayan recibido sus candidatos presidenciales durante la campaña electoral 2002-2006, asimismo la comisión podrá recomendar y dictaminar la legislación necesaria en materia electoral» (San José, Costa Rica: Departamento de Comisiones, Comisión Permanente de Asuntos Sociales, 21 de agosto de 2003), 15.

73 Ibíd., 18. 
probablemente, ese gesto de venir acá, porque esto habla muy bien de la democracia costarricense y habla bien de usted, de venir a exponer su verdad, a responder a los diputados. ${ }^{74}$

Dejando de lado las simpatías que le expresaron al empresario, había temas que no se podían ocultar o marginar. Uno de ellos eran las curiosas preferencias políticas de Jiménez. Una década antes, en la administración de Calderón Fournier (1990-1994), fungió como su principal asesor ad honorem y su padre, como se detalló páginas atrás, fue uno de los fundadores de la Unidad - PUSC. Ahora, se mostraba como un peculiar admirador de Arias Sánchez y cuando le increparon al respecto, respondió sin ambages:

\footnotetext{
Nunca he sido liberacionista y tampoco eso es ningún secreto. Esta es la primera vez en la vida política, no voy a decir que toda mi familia, porque algunos parientes cercanos han sido liberacionistas o fueron liberacionistas, pero en mi caso no. Esta es la primera vez que participé ayudando, porque tengo simpatía especial y creo que al país le convenía la presidencia de don Óscar Arias. ${ }^{75}$
}

Se estaba perfilando una característica común en la familia y también en las élites: sus elecciones políticas no tienen asideros ideológicos, en realidad, siguen criterios pragmáticos; la agenda de Arias era coincidente con los Jiménez-FIFCO y era suficiente motivo para adscribirse a su candidatura. Rodolfo aprovechó para relatar que muchas personas - del bloque dominante - le donaban a los partidos mayoritarios - en aquel entonces, el PLN y PUSC-, sin realizar distinciones de peso, solo pretendían no enemistarse con nadie e ¡impulsar la democracia!

La entrevista, puesto que no lucía como una comparecencia ni mucho menos un interrogatorio, se deslizaba entre la necesidad - $\_$o curiosidad? — de los diputados por entender lo sucedido y el respeto hacia una figura de gran poder en la Costa Rica contemporánea. El legislador socialcristiano, Gerardo González Esquivel, le increpó directamente sobre sí Abel Pacheco había sido «fabricado» por el empresariado local, a lo cual Rodolfo replicaba que sencillamente se trataban de amigos del entonces Presidente de la República y agregaba que ningún donativo estaba condicionado a posteriores favores políticos; todo lo habían hecho en aras de ayudar al país y a su sistema democrático.

En última instancia, el episodio de Jiménez Borbón y su peculiar presentación ante la Asamblea Legislativa, en apariencia, no tuvo repercusiones serias. A pesar de las pretensiones de regulación del financiamiento de partidos, los avances fueron mínimos. Asimismo, resultó llamativo que poco tiempo después de la cita de Jiménez con el Congreso, la Sala Constitucional aprobó la anhelada reelección, en los meses siguientes ocurrió la persecución y caída de Calderón 
Fournier y Rodríguez Echeverría, las figuras más desobedientes de las reuniones del año 2000 y cuyo proceso judicial contó con una desmedida participación de los medios de comunicación; con el diario La Nación y Televisora de Costa Rica - Canal 7, que atisbaron la hoguera condenatoria. ${ }^{76}$ Luego, Arias se alzaría con la victoria en 2006 y, a pesar de la resistencia civil, logró sellar el CAFTA en 2007. Mientras que en los siguientes 14 años, Rodolfo y su familia se convirtieron en donantes estrellas de la candidata victoriosa del PLN, Laura Chinchilla Miranda en 2010 y del partido cantonal, Curridabat Siglo XXI. Por supuesto, estas son meras coincidencias, pero se prestan para interesantes deducciones...

\section{Conclusiones}

El argumento central que se planteó a lo largo de las páginas anteriores estribó en que las élites de poder se conforman, no solo a través de la cooptación de recursos materiales o fortunas, sino, recurriendo a construcciones simbólicas, hábitos y otros ejercicios sociales — rituales - que demarquen su poder y pretendida autoridad. Prácticas simbólicas y tradiciones, tales como recurrir al mismo nombre para los hijos varones - como una forma de homologarse con dinastías y transfigurarse en figuras de pretendida inmortalidad-, matrimonios entre pares socioeconómicos, ceremonias fastuosas — bodas, fiestas privadas, asistencia a clubes de prestigio-, el recurso a la filantropía, el apego a ciertos valores y moralidad —en este caso, la cristiana católica-, entre otras.

A todo lo anterior, se debe hacer hincapié en que estas prácticas son - de base- meras ficciones o tergiversaciones históricas. Por ello, exigen repetición constante, ejemplo de ello es el uso continuo, empleando diferentes medios de comunicación, de las apologías en torno a miembros de la familia; así como la imprecisión, son «padres de la patria», pero su papel exacto se perdió en las nieblas de una época muy lejana. La estrategia, que pareciera se ha empleado por casi dos siglos, no es ofrecer detalles concisos, sino reiterar palabras clave, que se convierten en estereotipos que tratan de conformar a los arquetipos de la familia, como lo son hombres de honor, cultos, probos, diligentes y otros sinónimos que fueron expuestos en citas textuales antes descritas.

Para ser más precisos, se puede tomar el caso insigne de Ramón Jiménez, en la primera mitad del siglo XIX. Si bien, contó con una modesta riqueza que lo diferenció del grueso de sus contemporáneos, su papel político y su dominio social fueron limitados y, en la práctica, fue, a lo sumo, un actor secundario de los procesos decisivos de dicho contexto. Lo interesante radica en que se construyeron discursos posteriores que lo encumbraron, escritos por otros miembros

76 Jaime Solera Bennett, primogénito de Rodolfo, ha sido socio de Canal 7, en empresas como Talamanca Verde, Sociedad Anónima. Francisco Robles Rivera, «Los de entonces ya no son los mismos. Acumulación por desposesión en la última década en El Salvador y Costa Rica», Anuario de Estudios Centroamericanos, n. 37 (2011): 127, https://revistas.ucr.ac.cr/index.php/anuario/article/view/1120. 
de la familia o, como ha sido la norma hasta el presente, por amigos o periodistas comisionados para tal fin. Por otra parte, esta es una sociedad con un fuerte anclaje en el mundo colonial, donde las relaciones sociales son indispensables y, sobre todo, el prestigio, el cual se acumulaba, en gran parte, gracias a las obras insignes de los antepasados - conquistador, servidor de la Corona - y las buenas recomendaciones de los amigos.

De los más reconocidos hijos de Jiménez Robredo, José Manuel aportó poco al caudal general de riqueza, ${ }^{77}$ limitándose a preservar un nombre de respeto y tradición en la vieja metrópoli, mientras que Jesús Jiménez y su descendencia le han dado al clan uno de sus recursos históricos más importantes: célebres presidencias y el estatuto de beneméritos de la patria. Por ser los miembros más reconocidos públicamente, le han permitido, a la familia, una cierta influencia política tras bastidores, que se extendió a lo largo del siglo XX y los albores del XXI.

Se debe insistir - discursivamente - en que los Jiménez eran una familia de origen colonial y de la vieja Cartago, esto les facilitó el acceso a puestos y conocimientos reservados para unos pocos; en este punto fue central el ejercicio de la abogacía, sobre todo en figuras como Manuel Vicente Jiménez Oreamuno y su hijo, Lico. No obstante, en el campo de la cultura de élites, no fue su carrera profesional o empresarial lo que terminó destacando, sino la construcción idealizada de que fueron grandes hombres, funcionarios públicos o líderes de su clase social, como lo fue el caso de Jiménez Ortiz, exaltado como representante de los cafetaleros entre las décadas de 1930 y 1940 . Otro rasgo de este último es que bien puede ser considerado como un personaje olvidado, en favor de su célebre primo, Ricardo Jiménez Oreamuno. Este proceso no fue fortuito, ya que al estudiar con detalle la trayectoria de un individuo como Lico, se pueden ofrecer luces acerca de la formación histórica de la riqueza, puesto que sus conocimientos, lazos matrimoniales, cargos estatales, contactos con empresarios de la época, espacios de socialización, entre otros, fueron los facilitadores de su ascenso al poder; sin dejar de lado, las herencias que había acumulado su familia por décadas. Es decir, no era el prestigio, la probidad o el destino los que habían jugado un papel preponderante en su estatus de élite, era un largo proceso histórico el que medió.

Además, no se quiere degenerar, en una visión afín al mero historicismo, el poderío de la familia; este no era predestinado por su pasado, sino que fue un proceso, hasta cierto punto, acumulativo, en el que mediaron las prácticas que ya se habían afianzado, como las alianzas entre clanes dominantes, así como la insistencia en presentarse como hombres honorables - el patriarcado de por medio - y demás calificativos. Era, si se nos permite la metáfora, la transmutación de los títulos nobiliarios en el uso recurrente de los ancestros y el apelativo al pasado idealizado - la noble Cartago - ; pero, en esencia, eran formas de

77 Aunque una reinterpretación más sencilla estribaría en que «reinvirtió» en la alta educación de sus hijos, sobre todo de Manuel Vicente y ello, redituaría con creces en las siguientes décadas. 
encubrir el acaparamiento de la riqueza e, inclusive, el despojo que estas élites habían llevado a cabo durante décadas y hasta siglos. ${ }^{78}$

El punto en el que se quiere desembocar es que, cuando Manuel Jiménez de la Guardia o su hijo, Jiménez Borbón, intensificaron sus prácticas no solo de caridad, sino la designación directa de figuras políticas, por mucho, estaban replicando o actualizando las viejas prácticas que sus ancestros habían comenzado a experimentar. En palabras más concretas, las reuniones en sus mansiones eran convocadas, en esencia, porque los grandes patricios de Costa Rica así lo habían querido, eran ricos y sus ancestros célebres e influyentes; con ello se justificaba escuchar su - sabio - consejo o acatar sus directrices, al final de cuentas, tenían experiencia de sobra, ya que fueron partícipes de la historia misma del país, aunque su actuación en muchos momentos era más que secundaria. Habían acumulado poder y prestigio, ahora reclamaban el derecho a utilizarlo.

Por último, de ninguna forma se defiende una visión anacrónica, no se trata de que las élites contemporáneas, como la familia Jiménez, equivalen a grupos coloniales; el punto central es que utilizan herramientas discursivas y el recurso del prestigio; con fuerte tonos románticos y neoconservadores, apelan al pasado, para mitificarlo y, con ello, apoyar el sostenimiento de su poderío. Además, en última instancia dan muestra de la fragilidad del sistema democrático costarricense, permeado por prácticas que en el fondo son autoritarias y con baja representatividad real, ya que se trata de gobiernos que sirven en primer lugar a los grupos oligárquicos y que, de forma marginal, atienden al resto de la ciudadanía.

\section{Bibliografía}

Aguilar Machado, Alejandro. El licenciado Manuel Fco. Jiménez Ortiz. San José, Costa Rica: Trejos Hermanos, 1955.

Alpízar, Claudio. Noche sin tregua, entrevista a Miguel Ángel Rodríguez Echeverría. San José, Costa Rica, 24 de enero de 2013. https://www.youtube. $\mathrm{com} / \mathrm{watch}$ ? $\mathrm{v}=\mathrm{yTdoGloAiJU \& \text {feature } = \text { share. }}$

Álvarez Sousa, Antonio. «El constructivismo estructuralista: La teoría de las clases sociales de Pierre Bourdieu». REIS: Revista Española de Investigaciones Sociológicas, 75 (1996): 145-172. http://www.reis.cis.es/REIS/ jsp/REIS.jsp?opcion $=$ articulo\&ktitulo $=1163 \&$ autor $=\mathrm{ANTONIO}+\% \mathrm{C} 1 \mathrm{~L}-$ VAREZ+SOUSA.

Araya Pochet, Carlos. «La minería en Costa Rica (1821-1843)». Revista de Historia, 2 (enero-junio, 1976): 84-125. https://www.revistas.una.ac.cr/index. php/historia/article/view/11925.

78 Lo cual hemos detallado en otras publicaciones, especialmente, el acaparamiento de tierras en la futura Turrialba o el proceso por el cual se constituyó la FIFCO como un imponente monopolio cervecero de alcance ístmico. Marchena Sanabria, Formación histórica de las élites costarricenses a través del estudio de caso de la empresa "Florida Ice and Farm Company"... 
Archivo Nacional de Costa Rica. Serie Juzgado de lo Contencioso Administrativo . $^{\circ}$ 3833. San José, Costa Rica: ANCR, 22 de agosto de 1891.

. Serie Protocolos Coloniales n. 1147. San José, Costa Rica: Archivo Nacional de Costa Rica, 16 de diciembre de 1848: folios 153v-157v.

Asamblea Legislativa. Expediente n. ${ }^{\circ}$ 15.0002. Acta de Sesión Ordinaria No 29. «Comisión especial investigadora del financiamiento de los partidos políticos y las donaciones que hayan recibido sus candidatos presidenciales durante la campaña electoral 2002-2006, asimismo la comisión podrá recomendar y dictaminar la legislación necesaria en materia electoral». San José, Costa Rica: Departamento de Comisiones, Comisión Permanente de Asuntos Sociales, 21 de agosto de 2003.

Barahona Jiménez, Luis. Manuel de Jesús Jiménez. San José, Costa Rica: Departamento de Publicaciones del Ministerio de Cultura, Juventud y Deportes, 1976. Baudrit, Fabio. «Manuel Francisco Jiménez Ortiz». La Nación, 22 de abril de 1952, 4. Brenes Tencio, Guillermo. «La nación costarricense en duelo: los funerales del expresidente Jesús Jiménez Zamora (1897)». Acta Republicana Política y Sociedad, n. ${ }^{\circ}$, año 5 (2006): 3-15.

. "Ángeles funerarios del Cementerio General de Cartago, Costa Rica». Boletín de Monumentos Históricos, n. ${ }^{\circ}$ 19, tercera época (mayo-agosto, 2010): 150.

Burckhardt, Jacob. La cultura del Renacimiento en Italia. Madrid, España: Editorial EDAF, 1982.

Calderón Hernández, Manuel. Elementos del imaginario en la Costa Rica precafetalera. Cuadernos de Historia de las Instituciones de Costa Rica, 25. San José, Costa Rica: Editorial de la Universidad de Costa Rica, 2015.

Castegnaro, Marta. «Día histórico. Manuel Jiménez de la Guardia». La Nación, 25 de setiembre de 1987, 17B.

Dobles, Aurelia. "Filmar el soplo creador". La Nación, 17 setiembre 2000, Áncora. http://wvw.nacion.com/ancora/2000/septiembre/17/ancora1.html.

Documentos para escribir la historia de la revolución de Costa Rica, que estalló en fin de septiembre del año de 1835 copiados por un costarricense de los originales, que obran en el archivo del gobierno e impresos en San José a 15 de enero de 1836. San José, Costa Rica: Imprenta de la Paz, 1836.

Edelman, Marc; Fabrice Lehoucq; Steven Palmer e Iván Molina. Ciencia social en Costa Rica. Experiencias de vida e investigación (Heredia, Costa Rica: Editorial de la Universidad Nacional, 1998.

Esquivel, Mynor y Jorge Guzmán Loría, Cartago, «Convento de los padres capuchinos: una virgen de talla italiana», Revista Pasos de Fe (12 de setiembre 12 de 2012): párrafos 2 y 3. http://www.revistapasosdefe.com/?p=3285.

Fernández Montúfar, Joaquín. Historia ferrovial de Costa Rica. San José, Costa Rica: Galería del progreso nacional, 1934. 
Fernández, Andrés. «Un edificio del Club Unión, entre dos incendios». La Nación 22 de noviembre de 2015. http://www.nacion.com/ocio/artes/incendios_0_1525847425.html.

Florida Ice and Farm Company. FIFCO. Viviendo nuestro propósito. Reporte integrado 2015. San José, Costa Rica: FIFCO, 2015.

Gálvez, Omar, «Propondrán reducir en tiempo y en dinero campaña electoral». La Nación, 28 de mayo 1975, 10A.

Guardia, Víctor. Memorias del general don Victor Guardia. San José, Costa Rica, sin año.

Gutiérrez, Pedro Rafael. 100 años de historia a través de La Prensa Libre. San José, Costa Rica: Impresora Costarricense S.A., 1989.

Hall, Stuart. Sin garantías. Trayectorias y problemáticas en estudios culturales.

Popayán, Colombia: Editorial de la Universidad del Cauca, 2014.

Jiménez, Rafael. Juan Viñas dentro del contexto histórico nacional. Heredia, Costa

Rica: Departamento de publicaciones de la Universidad Nacional, 1992.

Jiménez Matarrita, Alexander. El imposible país de los filósofos. San José, Costa

Rica: Editorial de la Universidad de Costa Rica, 2008.

Jiménez Oreamuno, Manuel de Jesús. «Domingo Jiménez», Revista de Costa Rica, n. ${ }^{\circ} 8$ y 9, año II (abril-mayo 1921): 229-235.

. Noticias de antaño. Tomo I (San José, Costa Rica: ENUED, 2011).

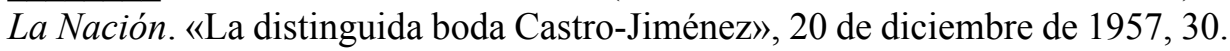

La Nación. «La distinguida boda de hoy Jiménez-Solera», 16 de diciembre de $1959,44$.

La Nación. «Arias: me embarcaron», 24 de mayo de 2000. http://wvw.nacion.com/

ln_ee/2000/mayo/24/pais2.html.

La Nación. «Una muestra de valor constante», 16 de noviembre de 1973, 4A.

La Nación. «Final del torneo de apertura a 36 hoyos, estilo medal pley termina con

el brillante triunfo de Rodolfo Jiménez Borbón», 25 de abril de 1960, 24.

La Nación. «INCAE: sinónimo de preparación solvente en materia de administración de empresas», 11 de setiembre de 1970.

La Nación. «Nómina de candidatos a diputados en todo el país», 8 de enero de 1970, 29.

La Nación. «Presidencia de la República no ha violado ninguna ley», 23 de julio de 1971,1 y 74.

La Nación. «En cumplimiento de lo que dispone la Ley No. 6220 del 20 de abril de 1978, publicada en el alcance No. 78 de la Gaceta No. 89, La Nación, S.A., da a conocer la lista completa de las personas físicas y de los accionistas de las personas jurídicas dueñas de acciones de esta empresa», 30 de junio 2010, 20A-21A. La República. «Aprobado proyecto que salva actividad azucarera del país», 14 setiembre 1979, 3.

La República. «Periodismo de luto», 31 de octubre de 1990, 2A. 
López, Grettel y Reinaldo Herrera (eds.). Ensayos en honor a Fernando Trejos Escalante. Academia de Centroamérica y ANFE, San José, 2004.

Lucena Salmoral, Manuel et al. Historia de Iberoamérica. Tomo III. Madrid, España: Cátedra, 2008.

Madrigal Muñoz, Eduardo, «Poder económico y lazos sociales de una élite local en los últimos años del régimen colonial y en la Independencia: Costa Rica, 1821-1824», Caravelle, 101 (2013): 87-108. doi: https://doi. org/10.4000/caravelle.575.

Marchena Sanabria, Jorge. Formación histórica de las élites costarricenses a través del estudio de caso de la empresa "Florida Ice and Farm Company" y su asociación con la familia Jiménez. Producto del proyecto de investigación 818-B6-090 del CIICLA, Universidad de Costa Rica. En prensa.

Mata Gamboa, Jesús. Monografía de Cartago. Cartago, Costa Rica: Editorial Tecnológica, 1999.

Matute, Ronald. «Oscar Arias con fuerte imagen», La Nación, 29 de setiembre de 1998. http://wvw.nacion.com/ln_ee/1998/septiembre/29/pais1.html.

Mills, Charles Wright. La élite del poder. México: Fondo de Cultura Económica, 1975.

Molina Jiménez, Iván. «Espías visibles, sorpresas esperadas y tiros sin puntería. El golpe de Guardia de 1870», Anuario de Estudios Centroamericanos, 20 (1994): 153-168. https://revistas.ucr.ac.cr/index.php/anuario/article/view/3229.

Monge Alfaro, Óscar. Historia del pueblo de Cacao de Alajuela. Alajuela, Costa Rica: documento inédito, 2009.

Mora, José Luis. «Forjadores de sueños», Actualidad Económica Cámara de Comercio de Costa Rica, 10, n. 8 (1995).

Murillo, Álvaro. «PLN: tres años después del abandono de la campaña». Semanario Universidad, 28 febrero 2017. https://semanariouniversidad.com/pais/ pln-tres-anos-despues-del-abandono-de-la-campana/.

Oconitrillo, Eduardo. Los grandes perdedores. Dieciocho politicos costarricenses. San José, Costa Rica: Editorial Costa Rica, 2000.

Páginas Ilustradas. «Licenciado don Manuel Vicente Jiménez», n. 182, año V (26 de enero de 1908).

Paige, Jeffery. Coffee and Power. Revolution and the Rise of Democracy in Central America. Boston, Massachusetts: Harvard University Press, 1998.

Pandemónium. «El Lic. Manuel Vicente Jiménez», año II (marzo, 1903).

Penabad, José María. «Reelección empezó con el azúcar...». Ojo, 7 febrero 2001, 3.

Poder Ejecutivo de la República de Costa Rica. Decreto Ejecutivo $n^{\circ} 27488$. San José, Costa Rica: Presidencia de la República y Ministerio de Cultura, Juventud y Deportes, 2 de noviembre de 1998. 
Porras, Manuel. «El historiador Manuel de Jesús Jiménez Oreamuno». Mis libros con notas, 10 de abril de 2016 http://mislibrosconnotas.blogspot.com/2016/04/ el-historiador-manuel-de-jesus-jimenez.html.

Porras Jara, Carlos. Los primeros cien años de la Florica Ice \& Farm Co. San José, Costa Rica: MasterLitho, 2010.

Revista de Costa Rica. «Don Ramón Jiménez», número 1, año III (15 de setiembre de 1921).

Revista del Instituto de Defensa del Café de Costa Rica. «El viaje de nuestro director Lic. Don Manuel Francisco Jiménez Ortiz», n. ${ }^{\circ}$ 5-6, tomo I, (marzo-abril, 1935).

Revista del Instituto de Defensa del Café de Costa Rica, n. ${ }^{\circ} 107-108$, tomo XIII (setiembre-octubre, 1943).

Robles Rivera, Francisco, «Los de entonces ya no son los mismos. Acumulación por desposesión en la última década en El Salvador y Costa Rica», Anuario de Estudios Centroamericanos, 37 (2011): 105-137. https://revistas.ucr. ac.cr/index.php/anuario/article/view/1120.

Romero, Javier de Diego, «El concepto de “cultura política” en ciencia política y sus implicaciones para la historia», Ayer, 61, n. 1 (2006): 233-266. https:// www.jstor.org/stable/41324963.

Sáenz Carbonell, Jorge Francisco. Agapito Jiménez: el canciller. San José, Costa Rica: Ministerio de Relaciones Exteriores y Culto, 2016.

. Don Joaquín de Oreamuno y Muñoz de la Trinidad: vida de un monárquico costarricense. San José, Costa Rica: Editorial de la Universidad Estatal a Distancia, 1994.

Sanabria Martínez, Víctor. Genealogías de Cartago hasta 1850. Tomo I. San José, Costa Rica, 1957.

Solís Avendaño, Manuel, «La élite caritativa y la institución psiquiátrica: una lectura desde los años cuarenta», Revista de Historia, n. ${ }^{\circ}$ 53-54 (enero-diciembre, 2006): 115-141.

. La institucionalidad ajena. Los años cuarenta y el fin de siglo. San José: Editorial de la Universidad de Costa Rica, 2006.

Stone, Samuel. La dinastía de los conquistadores. San José, Costa Rica: EDUCA, 1982.

Toledo, Ricardo. «El gesto de una dama», La Nación, 24 de abril de 1958, 31.

Tribunal Supremo de Elecciones. Contribuciones a los Partidos Políticos - C.SXXI. Periodo electoral 2006-2010. San José, Costa Rica: TSE, febrero 2010.

Valenzuela, Rafael. «El arte de gobernar», La Nación, 8 de noviembre de 1966, 8. Zeitlin, Irving. Ideología y teoría sociológica. Buenos Aires, Argentina: Amorrortu, 2006. 
Revista de Historia N. ${ }^{\circ} 81$

ISSN: $1012-9790 \cdot$ e-ISSN: 2215-4744

DOI: https://doi.org/10.15359/rh.81.3

http://www.revistas.una.ac.cr/historia

Enero - Junio, 2020 • pp. 67-101

\section{Anexo 1. Genealogía parcial de la familia Jiménez (siglos XVI-XIX)}

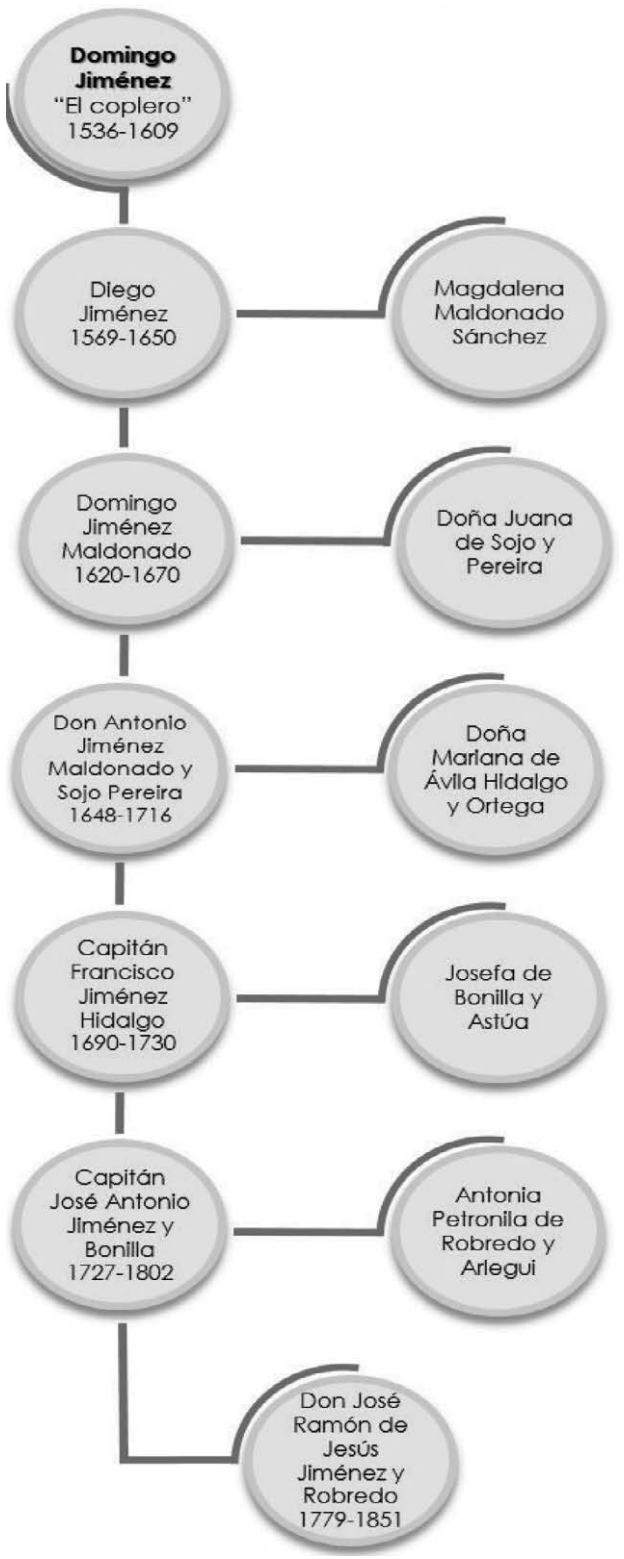

Fuente: Víctor Sanabria Martínez, Genealogías de Cartago hasta 1850. Tomo I (San José, Costa Rica: 1957); Jorge Francisco Sáenz Carbonell, Agapito Jiménez: el canciller (San José, Costa Rica: Ministerio de Relaciones Exteriores y Culto, 2016), 5-6.

Nota: No es una genealogía exhaustiva, por ende, no se presentan a todos los miembros de la familia. El objetivo es solo mostrar continuidades; asimismo, las fuentes consultadas no aportaron mayores datos con respecto a las mujeres. 
Anexo 2. Árbol genealógico parcial de la familia Jiménez: la «dinastía» de los Manuel

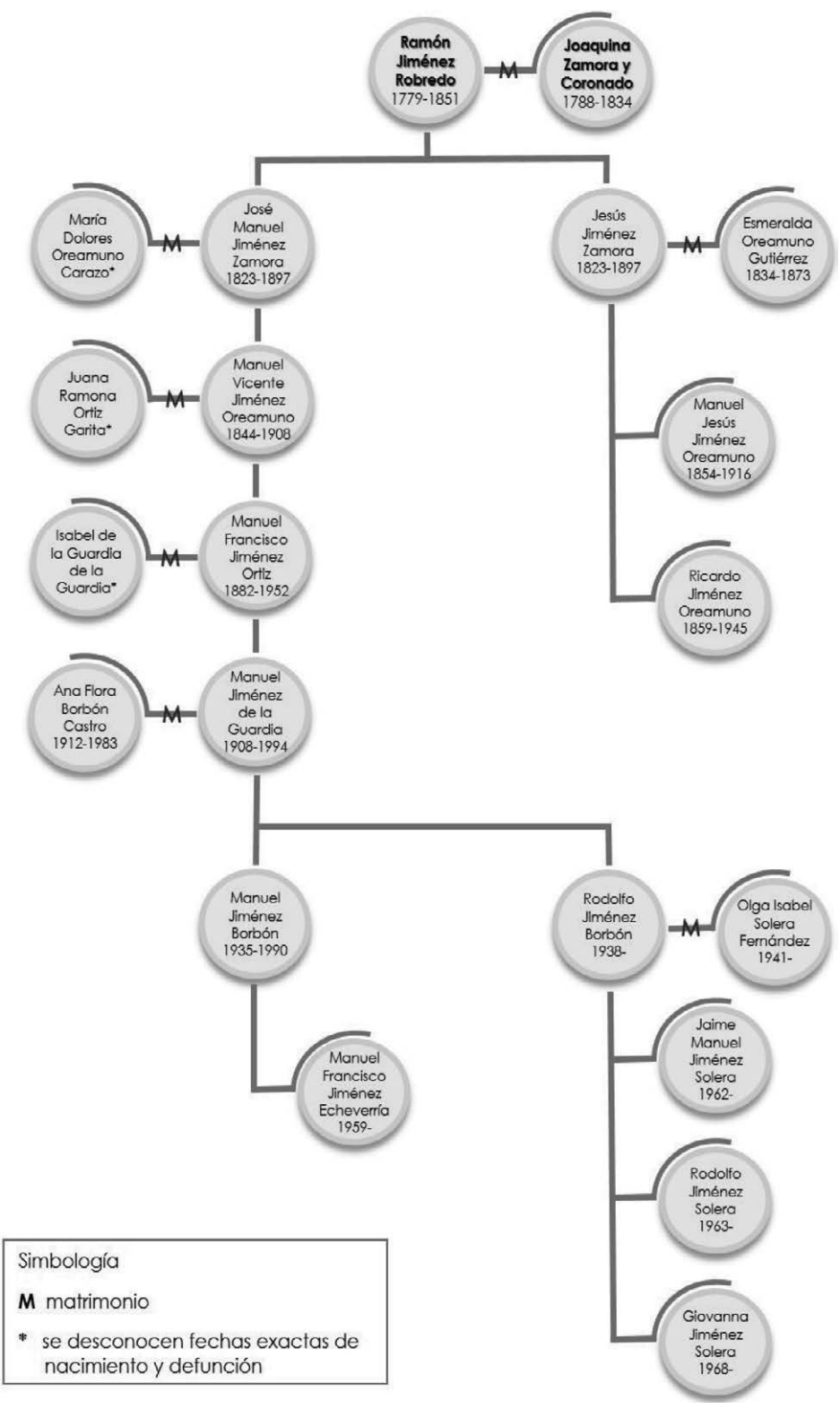

Fuente: elaboración propia a partir de los datos recabados por el proyecto Universidad de Costa Rica (UCR), Centro de Investigaciones en Identidad y Cultura (CIICLA), proyecto B6090, «Formación histórica de las élites costarricenses a través del estudio de caso de la empresa "Florida Ice and Farm Company" y su asociación con la familia Jiménez», que se desarrolló entre el 1 de enero de 2016 y el 31 de diciembre de 2017. 
